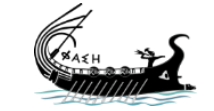

journal.phaselis.org

\section{Kotiaion Yazıtları Üzerine Notlar \\ I- Kotiaion Civarında İmparator Azatlıları ve Imparator Arazileri}

\author{
Notes on Inscriptions from Kotiaion \\ I- Imperial Freedmen and Imperial Estates Around Kotiaion
}

\section{Burak TAKMER}

The entire contents of this journal, Phaselis: Journal of Interdisciplinary Mediterranean Studies, is open to users and it is an 'open access' journal. Users are able to read the full texts, to download, to copy, print and distribute without obtaining the permission of the editor and author(s). However, all references to the articles published in the e-journal Phaselis are to indicate through reference the source of the citation from this journal.

Phaselis: Journal of Interdisciplinary Mediterranean Studies is a peer-reviewed journal and the articles which have had their peer reviewing process completed will be published on the web-site (journal.phaselis.org) in the year of the journal's issue (e.g. Issue III: JanuaryDecember 2017). At the end of December 2017 the year's issue is completed and Issue IV: January-December 2018 will begin.

Responsibility for the articles published in this journal remains with the authors.

Citation B. Takmer, "Kotiaion Yazıtları Üzerine Notlar I- Kotiaion Civarında İmparator Azatlıları ve Imparator Arazileri". Phaselis IV (2018) 423-445. http://dx.doi.org/10.18367/Pha.18025

Received Date: 03.12.2018 | Acceptance Date: 26.12.2018

Online Publication Date: 30.12.2018

Editing
Phaselis Research Project

www.phaselis.org 


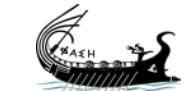

\title{
Kotiaion Yazıtları Üzerine Notlar I- Kotiaion Civarında İmparator Azatlıları ve İmparator Arazileri
}

\author{
Notes on Inscriptions from Kotiaion \\ I- Imperial Freedmen and Imperial Estates Around Kotiaion
}

\author{
Burak TAKMER*
}

Öz: Kotiaon kent merkezinden kısa süre önce yayımlanan bir yazıtta Phrygia'nın imparator azatlısı en erken procurator'u olarak Ti. Claudius Aniketos'un belgelenmesi hem Asia Eyaleti içinde Phrygia alt idare biriminin (eparkheia) en geç Claudius veya Nero zamanında varlığını kanıtlamakta hem de Synnada gibi Kotiaion'un da bu birimin idari merkezlerinden biri olabileceğini düşündürmektedir. Yazarın, makalenin sonunda derlediği Phrygia'nın bilinen tüm azatlı procurator'larına (App. 1) ve bunların altında görevli familia Caesaris üyelerine (App. 2) dair veriler Phrygia procurator'larının bölgedeki imparator mülkü tüm arazilerden ve mermer ocaklarından sorumlu olduklarını göstermektedir. Yazara göre tüm imparator mülklerinin idaresinin bu şekilde tek otorite altında birleştirilmesiyle arazilerden elde edilen tarımsal ürünlerin mermer ocaklarında çalışan işçilerin ihtiyaçları doğrultusunda daha verimli kullanılması amaçlanmıştır. MS II. yüzyılda Aslanapa ve Altıntaş Ovası'nda başta Sestullii gibi Italik kökenli zengin negotiator'lara veya Plancii gibi senatus sınıfı mensuplarına ait özel mülklerle birlikte imparator mülklerindeki genişleme Altıntaş Ovası'ndaki mermer ocakları gibi büyük üretim ve tüketim merkezlerinin varlığıyla açıklanabilir. Makale imparator mülklerinin genişletilme yötemlerinin değerlendirilmesiyle son bulmaktadır.

Anahtar sözcükler: Imparator azatlısı procurator'lar; imparator mülkü ocaklar/araziler; familia Caesaris; Choria Planciana; Sestullii; Yukarı Tembris Vadisi; Altıntaş Ovası; Dokimeion; Synnada; Prymnessos.

Abstract: The documentation of Ti. Claudius Aniketos as the earliest imperial freedman procurator of Phrygia in an inscription published recently from the city center of Kotiaon proves the existence of Phrygia as an administrative subdistrict (eparkheia) of the gubernatorial provincia Asia during the reign of Claudius or Nero at the latest. It also suggests that Kotiaion might have been one of the administrative centers of this subdistrict. The records of freedmen procurators of Phrygia (App. 1) and their subalterns, members of familia Caesaris (App. 2) compiled at the end of the article, indicate that the procurators of Phrygia were responsible for all the imperial estates and marble quarries in the region. The author considers that by combining the administration of all the imperial estates and quarries under a single authority, the agricultural products of the estates could be used more effectively in line with the needs of the people working in the quarries. The expansion of emperial estates in the plains of Aslanapa and Altıntass in the $2^{\text {nd }}$ century $A D$ along with the private properties of the rich negotiators such as Sestullii or that of senators such as Plancii can only be explained by the existence of marble quarries in Altıntas Plain as large production and consumption centers. The article ends with the evaluation of the ways of expansion of the imperial estates.

Keywords: Imperial freedmen procurators; Imperial quarries/estates, familia Caesaris, Choria Planciana; Sestullii; Upper Tembris Valley; Altıntaş Plain; Dokimeion; Synnada; Prymnessos.

* Doç. Dr., Akdeniz Üniversitesi, Edebiyat Fakültesi, Eskiçağ Dilleri ve Kültürleri Bölümü, Antalya. buraktakmer@akdeniz.edu.tr 
Giriş

Roma imparatorlarının finansal güçleri, mutlak otoritelerini koruyabilmenin temel dayanağıydı ${ }^{1}$. Servetlerinin ana kaynağı olan ve imparatorluğun muhtelif yerlerine dağılan mülkler aynı zamanda bulundukları bölgenin ekonomik, idari ve sosyal yapısında da belirleyici olmuşlardır. Başka bir ifadeyle imparator mülklerinin ${ }^{2}$ şu veya bu şekilde merkezden idaresi imparatorluğun en ücra köşelerinin dahi Roma'yla karşııklı etkileşiminde önemli rol oynamışlardır.

Batıda Rhyndakos (Mustafakemalpaşa/Orhaneli Çayı), kuzeyde Yukarı Tembris (Porsuk), güneyde Kaystros (Akar Çay) ve doğuda Yukarı Sangarios (Sakarya) vadileriyle çevrili Phrygia Epiktetos imparator azatlısı procurator'lara ve azatlı veya köle familia Caesaris üyelerine dair çok sayıda yazıt barındırmaktadır ${ }^{3}$ (bk. App. 1-2 ve Harita 1). Bunlar bölgede geniş imparator arazilerinin ve imparator mülkü mermer ocaklarının varlığını belgelemektedir ${ }^{4}$.

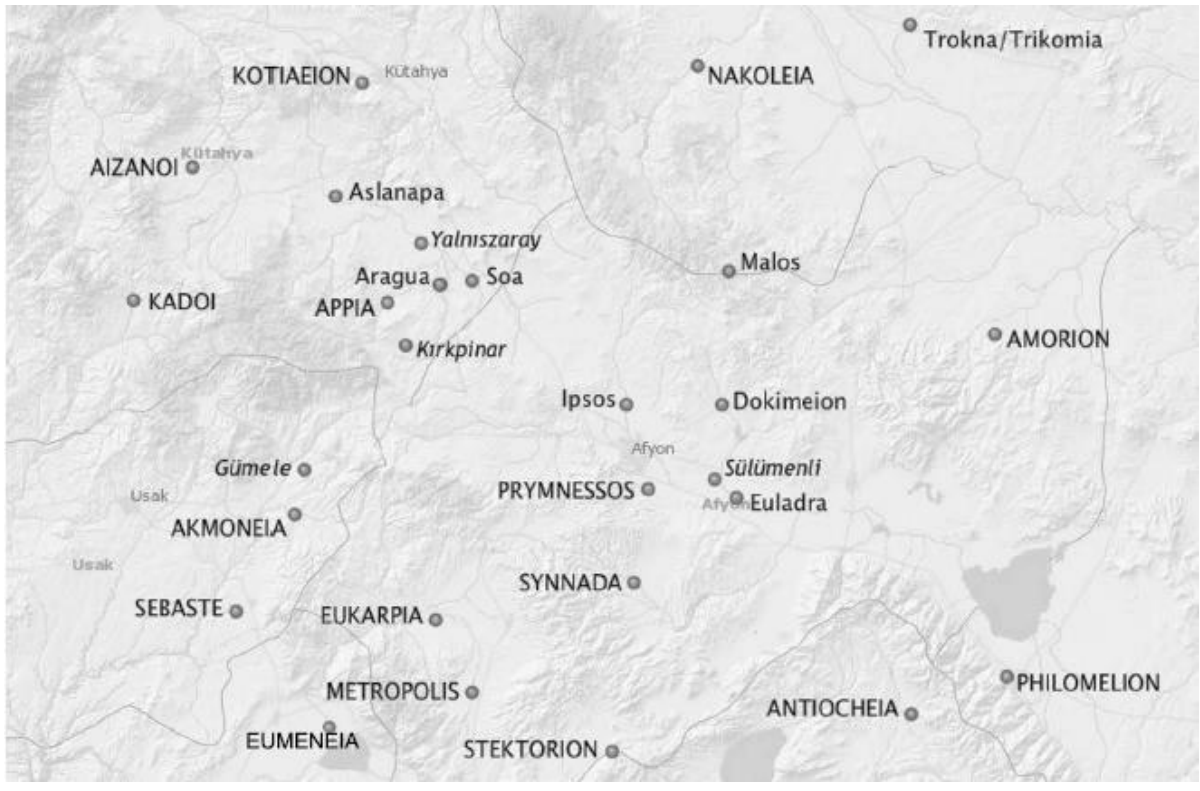

Harita 1. Appendices 1-2 için Harita (Dalla Rosa 2016, 302 fig. 1'den).

Kimi zaman özel bir şekilde 'Phrygia'nın procurator'u unvanını ${ }^{5}$ da taşıyan imparator azatlısı

1 İmparatorların mali güçleri hakkında genel bir değerlendirme için bk. Millar 1977, 133-201.

2 Imparator mülkleri için genel olarak bk. Pelham 1890; Schulten 1896; Beaudouin 1899; Hirschfeld 1902; Crawford 1976; Maiuro 2012.

3 Şimdiye kadar 28 imparator azatlısı procuratores ile 20 familia Caesaris üyesinin belgelendiği yazıtların yerleşimlere göre dağılımı şöyledir: Aizanoi (App. 1. 2, 12, 28); Akmonia (App. 1. 13-14); Appia (App. 2. 2, 14, 20); Dokimeion (App. 1. 18; 2. 4); Euladra (App. 1. 26-27; 2. 13); Eumeneia (App. 1. 15); Kotiaion (App. 1. 1, 3; 2. 18-19); Metropolis (App. 1. 5); Nakoleia (App. 2. 6, 9-11); Prymnessos (App. 1. 7, 23); Stektorion (App. 1. 8); Synnada (App. 1. 6-7, 11, 20-21; 2. 1, 3, 5, 7, 15-17); Trokna(da) (App. 1. 7, 9; 2. 12); Tymion (App. 1. 17). Bölge dışındaki verilerse şöyledir: Hierapolis (App. 1. 16); Laodicea ad Lycum (App. 1. 4); Laodicea Combusta (App. 1. 10); Pergamon (App. 1. 21-22, 24-25); Takina (App. 1. 23); Leptis Magna (App. 1. 2); Roma (App. 1. 5).

4 Phrygia'daki imparator mülkleri için bk. Broughton 1934, 220-222, 234-235; Broughton 1938, 648, 653, 659-661. Ayrica bk. Pelham 1890, 10-12; Anderson 1897, 417-422; Hirschfeld 1902, 301-303; Strubbe 1975, 229-250; Fant 1989, 9-10; MAMA X, xxxiii-xxxv; Mitchell 1993 (I), 158-160, 249 dn. 44; Tabbarnee - Lampe 2008, 68-69; Dalla Rosa 2016, 305-330.

5 App. 1. 6: T. Aelius Quintianus (proc. provinciae Phrygiae); App. 1. 7: M. Aur. Marcio (proc. prov. Frygiae);

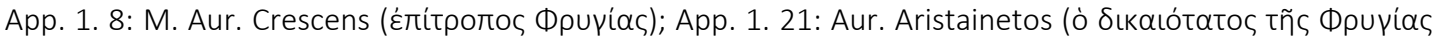

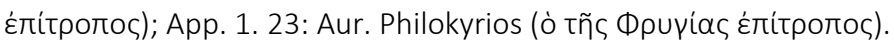


procurator'lar Phrygia'nın, Roma Imparatorluk Dönemi'nde Asia Eyaleti'nin bir tür alt idari birimi olabileceğini düşündürmektedir 6 . Ofisleri Ephesos'ta ${ }^{7}$ bulunan ve atlı sınıfı (ordo equester) mensubu olan Asia Eyaleti procurator'larının (procuratores Asiae) ${ }^{8}$ aksine, Phrygia procurator'ları imparator azatlısı (liberti Augusti) olup Synnada ile büyük ihtimalle Kotiaion'da ikamet etmekte ${ }^{9}$ ve eyalet valisine doğrudan rapor vermekteydiler ${ }^{10}$. Başka bir ifadeyle Phrygia'nın imparator azatlısı procurator'ları, Ephesos'ta ikamet eden atlı sınıfına mensup procurator'lara tabi değillerdi.

Asia Eyaleti içinde bu şekilde görece bağımsı idari bir alt birimin oluşturulmasında Phrygia'nın kapsadığı coğrafyanın genişliği, Batı ve Orta Anadolu arasındaki önemli ulaşım noktalarının buradan geçmesi ve en önemlisi Dokimeion ve Altıntaş Ovası'ndaki ocaklardan çıkarılan mermerler gibi bölgenin önemli ticari ürünleri belirleyici olmuş gözükmektedir. Asya'nın geri kalanı için söz konusu olan bir hazinenin yanında, Phrygia için ayrı bir hazineneye ihtiyaç duyulmasının sebebi de burada aranmalıdır. Hierapolis'te (Pamukkale) bulunmuş bir onurlandırma yazıına göre P. Aelius Zeuksidemos Aristos Zenon, Marcus Aurelius zamanında hem Asia

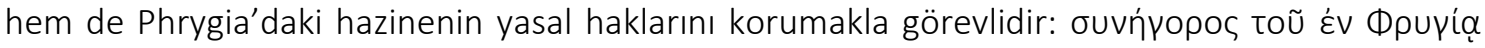

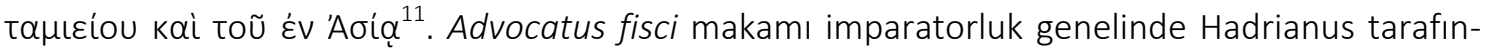
dan kurulmuş olmakla birlikte ${ }^{12}$, Phrygia için ayrı bir kasanın varlığı ve en azından finansal konularda ayrı bir idari birim oluşturması, M. Tullius Cicero'nun Kilikia valiliği zamanına (MÖ ca. 50) kadar geri gitmektedir. Cicero bu görev için tahsis edilmiş yıllık ödenekten (ex annuo sumptu qui mihi decretus) artan 1.000 .000 sestertii'yi - bu miktarın da kendilerine dağıtılmasını bekleyen askerlerin isteğine karşın - askeri kasaya değil, Phrygia ve Kilikia'daki resmi kasalara yatırmıştır (ut ego amicior invenirer Phrygum et Cilicum aerariis quam nostro) ${ }^{13}$. Cicero'nun görev yerinde Kilikia ve Phrygia için olmak üzere iki ayrı resmi kasanın bulunmasının, kendinden önceki iki vali gibi Cicero'nun da asıl görev yeri olan Kilikia eyaletinin yanısıra aslen Asia eyaletinin conventus merkezleri olmakla birlikte, o sırada Kilikia valisi olarak onun yetki sahasına dahil edilen Synnada, Apameia, Kibyra ile conventus merkezleri arasına daha sonradan dahil edilecek Philomelion ve bağlaşık yerleşimlerini de idare etmesiyle ilişkili olduğu açıktır. Her halükarda Aelius

6 Genel olarak bk. Vitale 2012, 68-77; 2015, 33-45.

7 Haensch 1997, 319-321.

8 Sorumluluk sahaları Phrygia'yı da kapsayan atlı sınıfı procurator'ları için bk. P. Aelius Zeuksidemos Aristos Zenon (advocatus fisci): IGR IV 819; PIR A 281; Pflaum 1960 no. 205; Ti. Claudius Serenus (proc. rationis privatae provinciae Asiae et Phrygiae et Cariae): IEphesos 647; PIR ${ }^{2}$ C 1017; Pflaum 1960 no. 283; Ulpius

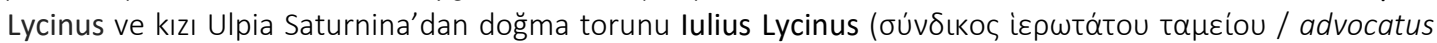
fisci): MAMA VI 373; PIR I 392; Kantor 2013, 150 no. 9; Vitale 2015, 37 dn. 19; Q. Cosconius Fronto (proc. ad vectig. XX her. per Pamphyliam, Asiam, Lyciam, Phrygiam, Galatiam, Insulas Cycladas; proc. ad vectig. XX per Pontum, Bithyniam, Pontum Mediterraneum, Paphlagoniam): CIL X 7583-7584; PIR ${ }^{2}$ C 1525; Pflaum 1960 no. 264; C. Titius Similis (praeposito vexillationum expeditionis per Asiam Lyciam Pamphyliam et Phrygiam): CIL II 484; PIR² T 272; Pflaum 1960, no. 330.

9 Synnada için bk. aş. dn. 16; Kotiaion için bk. aş. s. 431. MS III. yüzyılda oluşturulan regio Ipsina et Moeteana'nın idari merkezi ise Prymnessos'tu, bk. aş. s. 429.

10 Aizanoi yurttaşları arasında kentteki Zeus tapınağının kutsal alanının sınırları hususunda uzun süredir çözümsüz kalan anlaşmazlığın çözümü için MS 125/126 yılında Asia proconsul'u olan T. Avidius Quietus (PIR ${ }^{2}$ A 1409) kutsal alanın sınırlarının yeniden ölçtürülmesi görevini azatlı procurator Hesperus'a (App. 1. 2; $P I R^{2} H$ 165) vermiştir: CIL 3, 355 = OGIS 502 = IGR IV 571 str. C8: mi Hesper carissime, explores. Hesperus da incelemelerinin sonuç raporunu doğrudan valiye iletmiştir, str. D6-10: Ob hoc cum mihi iniun/xisses ut tibi renuntiarem quae / mensura esset clerorum circa re/gionem Aezaniticam misi in rem / praesentem.

11 Judeich 1898, no. 31 = IGR IV 819; krş. yk. dn. 8.

12 Hist. Aug. Hadrian. XX. 6: (Hadrianus) fisci advocatum primus instituit.

13 Cic. Att. VII. 1, 6. 
Zeuksidemos'un hem Asia'nın Ephesos'taki eyalet kasasının hem de özel olarak Phrygia'ya ait

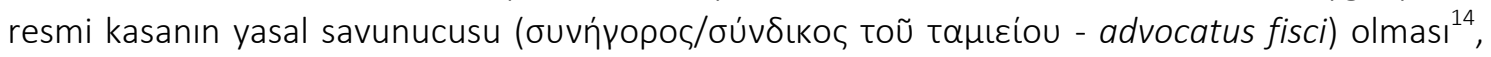
Phrygia'nın en geç MS II. yüzyılda ve en azından finansal konularda Asia eyaletinin bir alt idari birimi olarak kendi azatlı procurator'ları tarafından idare edildiğini belgelemektedir ${ }^{15}$.

Phrygia procurator'larının idari merkezlerinden birinin Synnada olduğu hususunda şüphe yoktur ${ }^{16}$. Bununla birlikte 2 . bölümde değerlendirilecek olan ve kısmen yeni belgelerden oluşan veriler Kotiaion'un da ikinci bir idari merkez olabileceğini düşündürmektedir. Bölgedeki mermer ocaklarının da dahil olduğu imparator mülklerini bu merkezlerden idare eden Phrygia procurator'ları imparator arazileriyle ilgili çıkan anlaşmazlıkların ${ }^{17}$ veya kırsal topluluklar arasındaki sınır meselelerinin çözümü ${ }^{18}$ gibi yargısal yetkilerin ${ }^{19}$ yanında başta Dokimeion ve Altıntaş Ovası'ndaki ocaklardan elde edilen mermerler olmak üzere bölgenin önemli ürünlerinin ihracı ${ }^{20}$

14 Synnada'da Ulpia Saturnina için alınan onurlandırma kararına (MAMA VI 373; krş. yk. dn. 8) göre bu

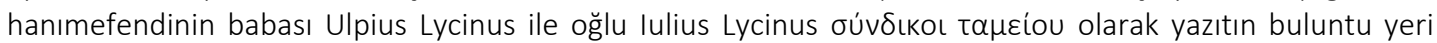
dikkate alındığında büyük ihtimalle Phrygia'daki resmi kasanın yasal haklarını savunmuş olmalıdırlar. Ayrica bk. Vitale 2015, 38.

16 Kent teritoryumunda imparator arazilarinde görevli azatlı muhasebeci ve yazmanlara ait çok sayıda yazıt ele

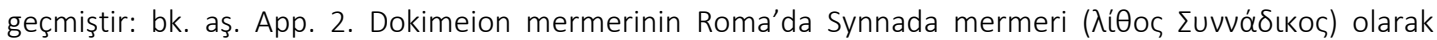
bilindiğini söyleyen Strabon, Synnada ile Dokimeion mermer ocakları arasındaki idari bağlantıyı doğrula-

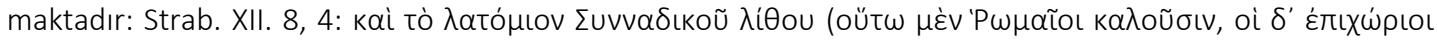

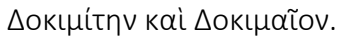

17 Synnada'da bulunan iki ayrı yazıtta Aur. Aristainetos (App. 1. 21; MAMA IV 63) ve Aur. Elpidephoros (App. 1.

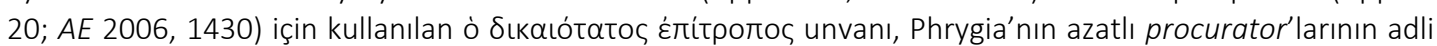
yetkilerine dair önemli bir veridir. Kaldı ki Aurelius Philokyrios (App. 1. 23) MS 213 yılında imparator mülkünün sınırları içinde kalan Takina sakinlerinin bölgedeki askerlerin yasadışı haraçlarına dair şikayetlerini

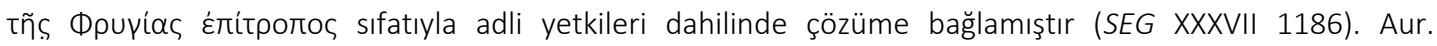
Philokyrios aynı yıl bu sefer Prymnsessos yakınlarındaki bir başka imparator mülkünde kalan Antimakheia ve

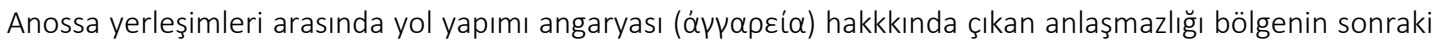
procurator'ları Aur. Threptos (App. 1. 26) ve Novellius'un (App. 1. 27) dahliyle çözüme bağlamıştır (SEG XIII 625). MS 205/208 yılında ise Septimius Severus ve Caracalla'nın yazıtta adı belirtilmeyen procurator'u (procurator noster, App. 1. 17) Tymion'da (Uşak yakınlarında) yine yasa dışı harçlar (inlicitae exactiones) meselesiyle uğraşmak zorunda kalmıştır (Hauken et al. $2003=$ AE 2003, 1690).

18 Kotiaion teritoryumunda bulunan ve Latince kalame alınan iki sınır yazıtına göre (MAMA X 255, 259) imparator azatlısı September (App. 1. 3) Hadrianus Dönemi’nde bölgedeki imparator arazisinin sınırlarının belirlenmesinde görev almıştır. Benzer bir şekilde Irenaios (App. 1. 5) da Metropolis (Tatarlı) yakınlarında Sibindos ve Euphorbion yerleşimleri arasındaki sınırın tespitini yapmıştır (CIL III 12237). Aizanoi yurttaşları arasında kentteki Zeus tapınağının kutsal alanının sınırları hususunda uzun süredir çözümsüz kalan anlaşmazlık MS 125/126 yılında Asia proconsul'u olan T. Avidius Quietus'un (PIR ${ }^{2}$ A 1409) görevlendirmesiyle azatlı procurator Hesperus (App. 1. 2; $P I R^{2} \mathrm{H}$ 165) denetiminde kutsal alanın sınırlarının yeniden ölçtürülmesi suretiyle çözüme kavuşturulmuştur (CIL III 355 = OGIS 502 = IGR IV 571).

19 Claudius patrimonium procurator'ları için yargı yetkisi getirmiş (Tac. ann. 12,60) olsa da bunlar ceza davalarıyla hukuk davalarının büyük bir kısmını göremiyorlar; bu davalar daha ziyade eyelet valisinin yetkisinde bulunuyordu: krş. Brunt 1990, 177. Bununla birlikte Ulpianus'un özel olarak belirttiği gibi fiscus'u ilgilendiren davalar fiili olarak procurator'un yetki sahasına devredilmektedir: Dig. I. 16, 9 pr.: Sane si fiscalis pecuniaria causa sit, quae ad procuratorem principis respicit, melius fecerit, si abstineat.

20 Leptis Magna'daki Hadrianus hamamlarının yazıtlı blokları ve Roma'da bulunan başka bloklar üzerinde Dokimeion mermer ocaklarından çıkarılan ilgili blokların o sırada Phrygia'daki imparator mülklerinin idaresinden sorumlu azatlı procurator'un denetiminde üretilip nakledildiğini belirten blok etiketleri bulunmaktadır. Buna göre Leptis Magna'daki Hadrianus hamamlarında kullanılan Dokimeion üretimi bloklar Hesperus'un (App. 1. 2) denetiminde (IRT 794d: sub cura Hesperi); Roma'da bulunan bloklar üzerindeki etiketler ise bunların Irenaios'un (App. 1. 5) denetiminde üretildiklerini belirtmektedir (ILS 8716a-b: sub cura Irenaei Aug. lib. proc.). 
gibi ekonomik ve ticari alanda da yetkilere sahipti. ${ }^{21}$ Dolayısıyla Phrygia procurator'larının adli ve mali yetkileri göz önüne alındığında, Roma Imparatorluk Dönemi'nde Phrygia Asia Eyaleti'nin imparator azatlısı procurator'ların yetkisinde bir alt idari birimi olmuş gözükmektedir ${ }^{22}$.

Phrygia procurator'ları başlangıçta Dokimeion'daki mermer ocaklarından sorumlu olmalıdırlar. Bu ocakların imparator mülküne ne zaman dönüştükleri yönünde yeterince veri yoktur. Bununla birlikte Augustus Dönemi yazarı Strabon daha önceleri küçük ebatlı taşların çıkarıldığını

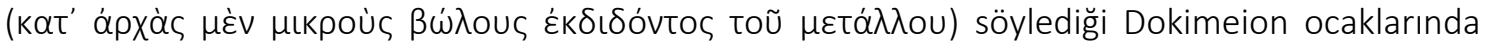

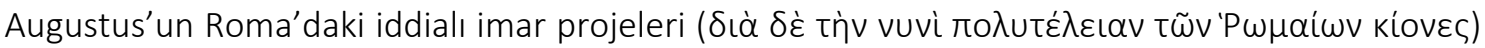
için çok büyük monolit blokların çıkalarılarak bu büyüklükte yüklerin denize kadar nakliyatı zor

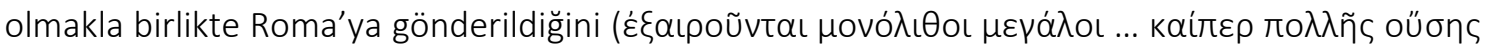

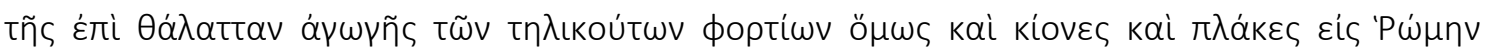
Kopí(ovtal) aktarır. ${ }^{23}$ Plinius Maior ise restorasyonu MÖ 13 yılında başlayan Aemilius Paulus Basilikası'nın sütunlarının takdire şayan Phrygia mermerinden üretildiğini not eder. ${ }^{24}$ Dolayısıyla Augustus'un Dokimeion mermer ocaklarını veya bunların bir kısmını şu veya bu yolla edindiği $i^{25}$ ve buradan çıkarılan mermerleri Roma'daki kapsamlı imar projeleri için kullandığı söylenebilir ${ }^{26}$. Her ne kadar Phrygia'da belgelenen en erken azatlı procurator Claudius veya Nero'nun azatlısı Ti. Claudius Aniketos (App. 1. 1) olsa da Dokimeion ocakları henüz Augustus zamanı gibi erken bir evrede imparator mülkü (patrimonium Caesaris) olmuş gözükmektedir.

Phrygia procurator'larının yetkileri MS II. yüzyılın ortalarından itibaren genişlemiş gözükmektedir. Procuratores provinciae Phrygiae unvanını taşıyan azatlı procurator'lar hem bunların idari merkezi Synnada'da (App. 1. 6,21) hem de Trokna (App. 1. 7) ve Takina (App. 1. 23) gibi Dokimeion mermer ocaklarından bir hayli uzak yerleşimlerde de belgelenmişlerdir. Hesperus (App. 1. 2; PIR H 165) hem Aizanoi'daki Zeus tapınağının sınırlarının yeniden ölçtürülmesiyle görevlendirilmiş (CIL III 355) hem de Leptis Magna'daki Hadrianus hamamlarında kullanılan bloklar üzerindeki mermer etiketlerinin işaret ettikleri gibi Dokimeion ocaklarında üretilen bu mermerlerin üretim ve nakliye sürecinden sorumlu olmuştur (IRT 794d). Benzer bir şekilde Irenaios (App. 1. 5) da hem Metropolis (Tatarlı) yakınlarında konumlu Sibindos ve Euphorbion yerleşimleri arasındaki sınırın tespitini yapmış (CIL III 12237) hem de Roma'da bulunan bloklar üzerindeki etiketlerde bunların üretim ve nakliyesinden sorumlu yetkili olarak kaydedilmiştir (ILS 8716a-b). Dolayısıyla Phrygia procurator'larının bölgedeki imparator mülkü tüm arazilerden ve mermer ocaklarından sorumlu oldukları açıktır. İmparator mülklü mermer ocakları ile arazilerin idaresinin tek otorite altında birleştirilmesindeki amaçlardan biri imparator mülkü arazilerden elde edilen tarımsal ürünlerin yine imparator mülkiyetindeki mermer ocaklarında çalışan işçilerin intiyaçları doğrultusunda daha verimli kullanılmasını sağlamak olmalıdır².

21 Procurator'ların görevleri için ayrıca bk. Schulten 1896, 66-67; Boulvert 1970, 416-441; Brunt 1990, $163-$ 187; Kehoe 2007, 81.

22 Vitale 2015, 33-45; krş. Türktüzün - Ünan 2017, 37 dn. 9.

23 Strab. XII. 8, 14.

24 Plin. nat. hist. XXXVI. 102: non inter magnifica basilicam Pauli columnis e Phrygibus mirabilem.

25 Ocatavianus-Augustus'un benzer şekilde Q. Hortensius'un Palatinus tepesindeki malikanesini ve kendi forum'unun inşası için başka mülkleri satın aldığı bilinmektedir: Suet. Aug. 72; res gest. D. Aug. XXI. 1). Augustus ayrıca MÖ 36 yılında veteran askerlere dağıtmak üzere, parasını kendi cebinden ödeyerek Italia'daki kentlerden araziler satın almıştır: Cass. Dio XLIX. 14, 5.

26 Phrygia mermerinin (pavonazzetto türü mermer) her daim imparator tekelinde olduğu ve MS II. yüzyıla kadar Roma dışında son derece nadir kullanıldığına dair bk. Dalla Rosa 2016, 318 dn. 57.

27 Dalla Rosa 2016, 325. 


\section{Phrygia'da İmparator Mülkleri}

Birçok imparator mülkünün bulunduğu Phrygia'nın, azatlı procurator denetimine en erken Hadrianus veya M. Aurelius zamanında verildiği yönünde bir communis opinio bulunmaktadır ${ }^{28}$.

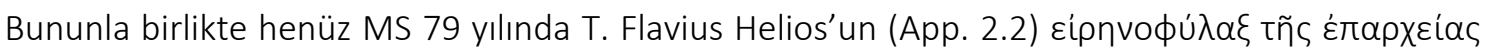
olarak Appia'da görevli olması ${ }^{29}$; eparkheia Phrygia idari alt biriminin halihazırda varlığını, dolayısıyla yukarıdaki yaygın görüşün yanlışığını belgelemektedir ${ }^{30}$. Kütahya Müzesi tarafından Servi Mahallesi kazılarında şimdiye kadar bilinen en erken azatlı Phrygia procurator'u olan Ti. Claudius Aniketos (App. 1.1) ile eşi Claudia Urbana'nın mezar yazııının ${ }^{31}$ günyüzüne çıkarılması, Phrygia alt idare biriminin en geç Claudius veya Nero zamanında varlığı yönünde güçlü bir kanıt sunmaktadır. Azatı procurator'lara dair bundan sonraki veriler ise MS II. ve III. yüzyıllara aittir (bk. App. 1). Buna karşın azatlı procurator'ların altında görev yapan familia Caesaris üyeleri arasında MS I. yüzyıla tarihlenen beş görevli bilinmektedir. Synnada'da Nero'nun tabularius'u olarak görevli Hyakinthos (App. 2. 1) bunlardan en erkene tarihlenenidir. Familia Caesaris üyesi diğer dört görevli ise Flavius'lar zamanına aittir (App. 2. 2-5: T. Flavius Helios, Ti. Claudius Onesimos, Saturninus ve [...]us Priamos). Appia teritoryumunun güney ucundaki Eyidemir'de bulunan ve Vespasianus'un azatlısı T. Flavius Helios (App. 2. 2) ile eşi Sextilia Hedone'nin Zeus Bennios için MS 79 yılına tarihli adaklarını içeren yazıtlar, Flavius Helios'un Phrygia alt idari

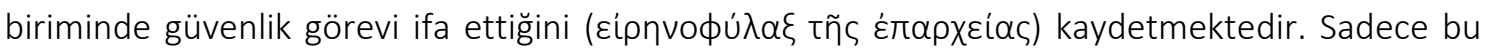
yazıtlarda belgelenen makam, bölge sakinleri arasında huzursuzluk yaşanmasına yol açabilecek kararnamelerde imparator ve merkezi yönetim adına düzeni ve hukuku tesis etmekle yükümlü olmalıdır. ${ }^{32}$ Atalarının yakın civarda bulunan Agrostea $^{33}$ köyü kökenli olmaları, Flavius Helios'un güvenlik görevini kendi memleketinde icra ettiğini göstermektedir. Imparatorların bu sırada Appia civarı ve Yukarı Tembris Vadisi'nde arazi edinmeleri olası gözükse de onların asıl ilgileri Altıntaş ilçesi sınırlarına yayılan mermer ocakları üzerinde yoğunlaşmış olmalıdır. Altıntaş, Alibeyköy, Kurtköy ve Çakırsaz köylerinde terk edilmiş bloklar üzerine kazınan ve MS 92 ile 156 yılları arasına tarihlenen mermer ocağı etiketleri ${ }^{34}$, bir yandan ocakların yayılım alanını, öte

28 Hadrianus zamanı için bk. Boulvert 1970, 294 dn. 209; Hirt 2010, 114; M. Aurelius zamanı için bk. Bowersock 1995, 85-98; Potter 1998, 270-274; Kantor 2013, 144. Drew Bear - Naour 1990, 1967-1981 no. 15-16.

30 Mitchell 1999, 29 dn. 51; krş. Vitale 2012, 74-77; 2015, 35.

31 Türktüzün - Ünan 2017, 36-37 no. 1.

32 Kearsley 2016, 526.

33 Appia teritoryumununda kalan Agrostea kırsal yerleşimi, Eyidemir'in güneydoğusunda yer alan Kırkpınar mevkiine yerleştirilebilir: Drew-Bear - Naour 1990, 1979-1980; MAMA X, xlii.

34 Altıntaş: MAMA X 72 = Christol - Drew-Bear 1986, 75-80 = Hirt 2010, App. 440 (MS 109?); MAMA X $71=$ Drew-Bear - Eck 1976, 315 = Waelkens 1985, 643 = Hirt 2010, App. 444 (MS 116?); ayrıca bk. Buckler et al. 1928, no. 233.

Alibeyköy: Drew-Bear - Eck 1976, no. 16 = Fant 1989, no. 642 = Hirt 2010, App. 439 (MS 92?); Drew-Bear Eck 1976, no. 17 = Fant 1989, no. 652 = Hirt 2010, App. 445 (MS 116); Drew-Bear - Eck 1976, no. 18 = Fant 1989, no. 662 = Hirt 2010, App. 446 (MS 116?); MAMA X 94 = Drew-Bear - Eck 1976, 315-316 = Hirt 2010, App. 453; Drew-Bear - Eck 1976, no. 19 = Fant 1989, no. 672 = Hirt 2010, App. 454; Drew-Bear - Eck 1976, no. 20 = Fant 1989, no. 682 = Hirt 2010, App. 455; ayrıca bk. Röder 1971, 312.

Kurtköy: MAMA X 122 = Hirt 2010, App. 438 (MS 92); MAMA X $123=$ Hirt 2010, App. 447; MAMA X $124=$ Hirt 2010, App. 441 (MS 116-156); MAMA X 125 = Hirt 2010, App. 442 (MS 114-116); MAMA X $126=$ Hirt 2010, App. 448; MAMA X 127 = Hirt 2010, App. 449; MAMA X $128=$ Hirt 2010, App. 450; MAMA X $129=$ Hirt 2010, App. 451; MAMA X $130=$ Hirt 2010, App. 452.

Çakırsaz: Drew-Bear - Eck 1976, no. 25; Fant 1989, no. 732 = Hirt 2010, App. 443 (MS 116); Drew-Bear Eck 1976, no. 21; Fant 1989, no. 692 = Hirt 2010, App. 456; Drew-Bear - Eck 1976, no. 22; Fant 1989, no. 
yandan da bunların imprator adına Dokimeion'da faaliyet gösteren müessesenin bir tür bayisi olarak hizmet gördüklerini belgelemektedirler ${ }^{35}$. Dolayısıyla mermer ocağı etiketleri üzerindeki en erken veri MS 92 yılına ait olsa da Yukarı Tembris Vadisi'ndeki ocaklar tıpkı Dokimeion'daki ocaklar için söz konusu olduğu gibi henüz Augustus zamanında imparator mülkiyetine geçmiş olmalıdır $^{36}$. Dokimeion ve Yukarı Tembris Vadisi'ndeki ocaklardan çıkarılan mermer $\rightarrow$ Synnada Apameia $\rightarrow$ Laodiceia ad Lycum $\rightarrow$ Tralleis $\rightarrow$ Miletos veya Ephesos güzergahı üzerinden ihraç edilmekteydi ${ }^{37}$.

İmparator kölesi Proculus'un (App. 2. 14) Karaağaç ${ }^{38}$; dispensator Augusti ${ }^{39}$ görevini yürüten Dionysios'un (App. 2. 14) ise Yapılcan ${ }^{40}$ civarındaki imparator arazilerinde familia Caesaris üyesi olarak hizmet gördüklerini belgeleyen yazıtlar Altıntaş Ovası'ndaki imparator mülklerinin MS II. yüzyılda mermer ocaklarının yanında tarım arazileriyle de genişlediklerini göstermektedir. Yapılcan'da bulunan bir başka yazıtta ise kendilerini Soa $^{41}$ ve Moitea ${ }^{42}$ arasındaki imparator

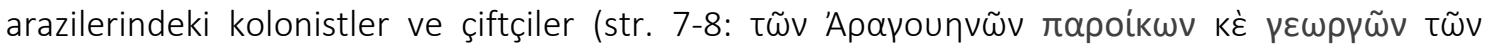

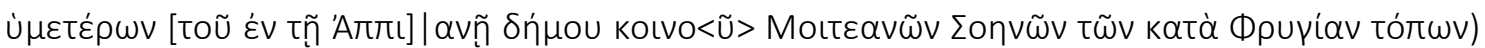
olarak tanımlayan Aragua ${ }^{43}$ köyü sakinleri, MS 244-247 yılları arasında bu arazilerde yetkili

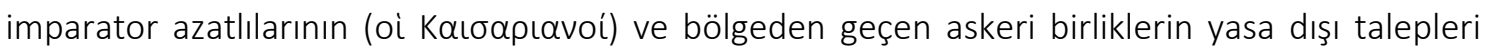
aleyhine Philippus Araps ve oğluna bir dilekçeyle şikayette bulunmuşlardır ${ }^{44}$. Dilekçeden anlaşıldığına göre Aragua, Soena et Moeteana bölgesinde yer almaktadır. Prymnessos'ta bulunmuş Latince bir mezar yazıtında ise imparator azatlısı Marcus Aurelius Victorinus (App. 2. 8), tabularius regionarius ${ }^{45}$ Ipsinae et Moeteanae olarak görev yapmaktadır. Bu veri Moeteana olarak bilinen bölgedeki imparator mülkünün idari açıdan ilkin MS II. yüzyılın sonu veya III. yüzyıIın başında Soa yakınlarındaki, daha sonra da MS 240'lı yıllarda Ipsos civarındaki imparator arazileriyle birleştirildiğini, dolayısıyla da söz konusu bölgenin Soa ile Ipsos arasında yer aldığını, ama idari merkezinin Prymnesos'ta bulunduğunu göstermektedir ${ }^{46}$.

702 = Hirt 2010, App. 457; Drew-Bear - Eck 1976, no. 23; Fant 1989, no. 712 = Hirt 2010, App. 458; DrewBear - Eck 1976, no. 24; Fant 1989, no. 722 = Hirt 2010, App. 459; ayrıca bk. CIL III Suppl. 12227-12229.

35 Fant 1989, 9-10; MAMA X, xxxiii; Hirt 2010, 303 dn. 244.

36 Altıntaş Ovası'ndaki mermer ocaklarının Tiberius zamanında imparator mülkiyetine geçtiği görüşü için bk. Strubbe 1975, 244; krş. MAMA X, xxxiii.

37 Hirt 2004, 119 dn. 15; Hirt 2010, 116.

38 MAMAX 136

39 Dispensator için bk. Weaver 1972, 224-226; 245-246; 250-252; Hirt 2010, 155-159; 253-257. Dokimeion'da görevli bir başka dispensator için bk. Christol - Drew-Bear 1986, 61.

40 CIL III 7002; Weaver, Repertorium 502 no. 3924.

41 Altıntaşta bulunan ve ethnikon'unun Eonvos formunda geçtiği üç adet yazıt (Drew-Bear - Naour 1990, 1989 dn. 292; IGR IV 603 ve MAMA X 69 = IGR IV 605) Soa'nın Altıntaş'a lokalizasyonunu kesinleştirmektedir, krş. Zgusta 1984, 579 § 1239; Belke - Mersich 1990, 385-386 s. v. Soa; MAMA X, xvi, xliv.

42 Bölgenin Soa ile Ipsos (modern Sipsin) arasında yer aldığına dair bk. Ballance 1969, 143; Strubbe 1975, $232-$ 236; Zgusta 1984, 392 § 824; Drew-Bear - Naour 1990, 1964 dn. 204; MAMA X, xvi-xvii, xliv.

43 Zgusta 1984, 87 § 85-8; Drew-Bear - Naour 1990, 1964-1965; MAMA X, xvi-xvii, xlii. Bir Aragua Köyü

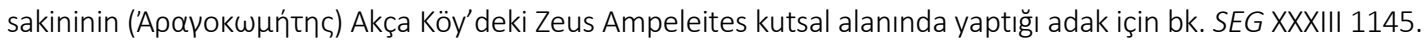

44 MAMA X 114 = CIL III I4I9I = OGIS 519 = IGR IV 598; ayrıca bk. Broughton 1938, 659-661; Rostovtzeff 1957, 741-742; Strubbe 1975, 231-232; Herrmann 1990, 28-33.

45 Ballance 1969, 143.

46 Ballance 1969, 143. 


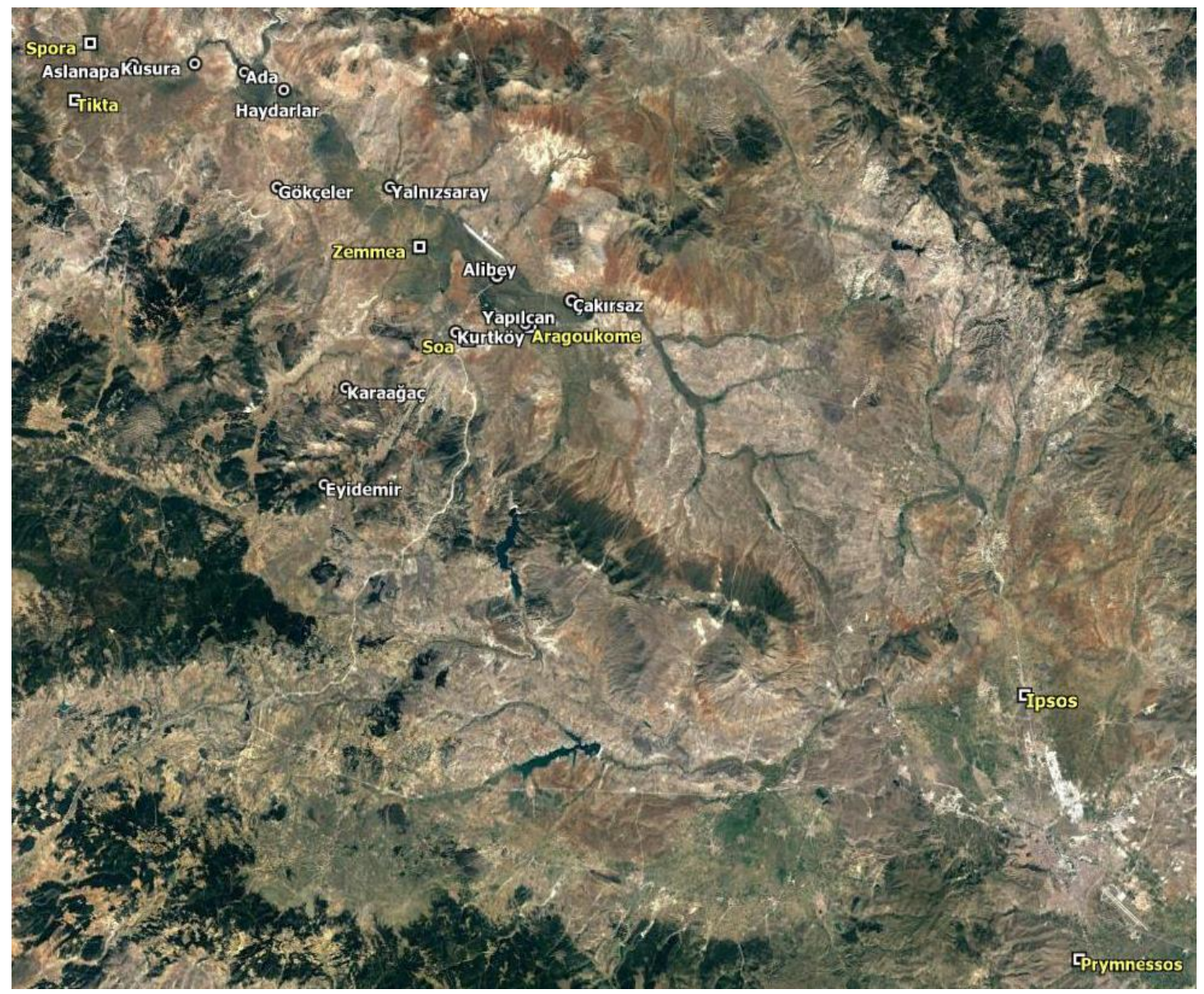

Harita 2. Altıntaş Civarındaki İmparatora Ait Araziler ve Mermer Ocakları için Harita

Dokimeion mermer ocaklarının Synnada'daki idari merkezden yönetildiğine (bk. yk. dn. 16) daha önce değinilmişti. Yukarıdaki veriler ise Altıntaş Ovası'ndaki ocakların en geç MS II. yüzyılın başından itibaren Prymnessos'taki bir başka idari merkezden yönetildiğini göstermektedir. Bununla birlikte Kütahya Müzesi tarafından Servi Mahallesi'nde yürütülen kazılarda ortaya çıkarılan yazıtlar Claudius zamanında Kotiaion'un da Phrygia'daki imparator mülklerinin idari merkezlerinden biri olabileceğini düşündürmektedir. Nitekim Servi Mahallesi buluntusu bir mezar yazıtı (yk. dn. 31), nomen gentilicum'un da işaret ettiği üzere Claudius veya Nero'nun azatlısı, dolayısıyla Phrygia'nın şimdiye kadar belgelenen en erken azatlı procurator'u olan Ti. Claudius Aniketos'un (App. 1. 1) Kotiaion'da ikamet ettiğini göstermektedir. Kütahya'da kopyalanan bir başka yazıtta ise adı okunamayan bir imparator kölesi, eşi Plotina ve kendisi için mezar yaptırmış ${ }^{47}$ imparator azatlısı adiutor tabularii ${ }^{48}$ olarak görevli Aurelius Hermes'in vatanına karşı yaptığı hizmetler nedeniyle imparator arazilerinde instrumentarius ${ }^{49}$ olarak görev yapan imparator azatlısı oğlu M. Aurelius Hermes Kotiaion'un Danışma ve Halk meclisi kararıyla onurlandırılmıştır ${ }^{50}$.

47 Buckler et al. 1925, no. 167.

48 Weaver 1972, 239-240; Hirt 2010, 114, 151-152, 159, 253, 256.

49 Hirt 2010, 256.

50 Türktüzün - Ünan 2017, 41 no. 6; anne Iulia Aphrodeisia'nın onurlandırılma kararına ilişkin yazıt için bk. Türktüzün - Ünan 2017, 43-44 no. 9. 


\section{Kotiaion Civarında İmparator Azatlıları ve İmparator Arazileri}

Kotiaion'un ${ }^{51}$ kent merkezi ve teritoryumundan ${ }^{52}$ bugüne kadar üç yüzün üzerinde yazıt yayımlanmıştır ${ }^{53}$. Bu yazıt külliyatı diğer birçok bilginin yanı sıra Aslanapa Ovası'nda Kotiaion teritoryumuna sınırdaş imparator mülklerine işaret eden veriler de içermektedir. Biri Kusura' $\mathrm{da}^{54}$ (yeni adı Esen), diğeri ise Aslanapa ile Gökçeler arasında ${ }^{55}$ bulunan ve Latince kaleme alınan iki sınır yazıtına göre imparator azatlısı September (App. 1. 3), Asia Eyaleti'nin Hadrianus Dönemi'nde equester sınıfı üyesi procurator'u olan Papirius Paullinus'un ${ }^{56}$ denetiminde imparator arazisinin sınırlarının belirlenmesinde görev almıştır. Her iki yazııın buluntu konumları Aslanapa Ovası'ndaki imparator arazisinin sınırının ovayı Adaköy ve Haydarlar civarında Yukarı Tembris Vadisi'nin batı ucundan ayıran sırt boyunca ilerlediğini göstermektedir. Aslanapa Ovası'ının diğer kesimlerinde imparator arazilerinin varlığına dair bugüne kadar bir veri bulunmadığına, ayrıca bu bölgede yer alan Spore ${ }^{57}$ ve Tikta ${ }^{58}$ köyleri arasında MS III. yüzyılın ortalarındaki sınırı belirleyen bir yazıtta ${ }^{59}$ imparator arazileriyle bağlantılı hiçbir görevli anılmadığına göre September'in görevli olduğu imparator arazisi Kusura ve Gökçeler arasında çizilen hattın doğusunda yer almış olmalıdır. ${ }^{60}$ Aslanapa ile Gökçeler arasındakine nazaran daha iyi korunan Kusura'daki sınır yazıtı Aslanapa Ovası'ndaki imparator arazisinin daha önceki sahipleri hakkında da bilgi içermektedir:

Imp(eratoris) Caesaris Traiani Hadriani Aug(usti) termini [ . . . ]cianorum per Papirium

Paullinum procur(ante) Septembre Aug(usti) lib(erto).

Yazıt ilgili araziyi "(praedia) [. . . .]cianorum" şeklinde tanımlamaktadır. Burada genetivus pluralis (çoğul tamlayan) formunda son kısmı korunan isim bir nomen gentilicum veya cognomen'den türemiş olmalıdır. Zira her ikisi de Hadrianus zamanında imparator arazisine

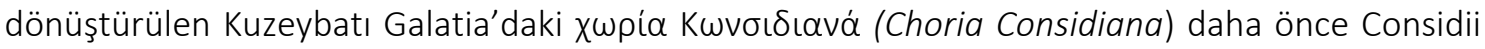
ailesinin $^{61}$, Güneydoğu Phrygia'daki Laodikeia Katakekaumene civarında bulunan praedia

51 Strab. XII. 8,12; Plin. nat. hist. V, 145; Ptol. geogr. V. 2, 23; Steph. Byz. s. v. Kotıázııv.

52 Kotiaion'un teritoryum sınırları için bk. Takmer 2018, Harita 1; krş. MAMA X, xvii.

53 Yazıtların yayım yerleri için bk. Takmer 2018, dn. 8.

54 MAMAX 255.

55 MAMAX $259=$ CIL III 7004 .

$56 P I R^{2}$ P 117. Yazıtın ilgili kısmını procur(atorem) şeklinde tamamlamak suretiyle azatlı procurator'un September değil, Papirius Paullinus olduğu önerisi için bk. AE 1993, 1511; krş. Vitale 2015, 37 no. 2 A.

57 Pınarbaşı: SEG XXXII 1287; Christol - Drew-Bear 1982, 33-34; Belke - Mersich 1990, 388-389 s. v. Spore; MAMA X, xliv.

58 Kışla Mevkii / Terziler: SEG XXXII 1287 = SEG XLI 1238; Belke - Mersich 1990, 388-389 s. v. Spore; French 1991, 57; MAMAX, xliv.

59 Christol - Drew-Bear 1982, 23-42.

60 Krş. MAMAX, xxxiii-xxxiv.

61 Anderson 1937, 18-21; Mitchell 1980, 1074-1075; 1982, 34-36; Güney 2016, 128-129; 2018, 56. Bu imparator mülkünün ilk sahiplerinin MÖ I. yüzyılda zengin bankerler ve vergi mültezimleri (publicani) olarak bilinen Considii ile bağlantılı olmaları, her ne kadar bu ailenin Anadolu’da varlığı yönünde bir veri bulunmasa da, mümkündür. Valerius Maximus MÖ 95 yılı consul'u L. Licinius Crassus'un publicanus olarak faaliyette bulunan Considius adında bir arkadaşını anmaktadır (Val. Max. IX. 1, 1). Bu şahsın, Catilina'nın darbe teşebbüsü sırasında özel şahıslara toplam on beş milyon sestertii tutarında verdiği kredileri ertelediği için senatus tarafından övülen (Val. Max. IV. 8, 3. Krş. Cic. Att. I. 12, 1) senator Q. Considius'un (Gruen 1974, 202 [MÖ ca. 74]) babası olma intimali yüksektir. MÖ ca. 63 yılı quaestor'u C. Considius Longus (Gruen 1974, 157 dn. 154, 176) ile MÖ ca. 54 yılında praetor olan M. Considius Nonianus (Gruen 1974, 173, 490 dn. 139) iç savaş sırasında Pompeius'un yanında yer almışlardır. Bu şahıslar arasındaki akrabalık ilişkisini belirlemek mümkün olmasa bile atlı sınıfı mensubu Considius Aequus ( $\left.P I R^{2} C 1279\right)$ ile praetor mertebesine kadar yükselmiş senatus sınıfı üyesi Considius Proculus'un $\left(P I R^{2}\right.$ C 1281) Tiberius zamanında farklı sebeplerle mahkum 
Quadratiana da vaktiyle Quadratus cognomen'ine sahip birinin özel mülkü ${ }^{62}$ için kullanılan adlandırmalar olarak benzer bir şekilde türetilmişlerdir. Her halükarda yazıtta baş kısmı korunmamış olan ismi tamamlamak için Perge'de ikamet eden Italik kökenli Plancii ailesi güçlü bir adaydır. Zira bu ailenin Imparatorluk Dönemi'nde, Choria Considiana'nın doğu komşuluğunda Akreina (ikizafer/ikikilise?) ve Phyle (Beyköy) yerleşimlerinin de dahil oldukları arazilerin sahibi olduğu bilinmektedir ${ }^{63}$.

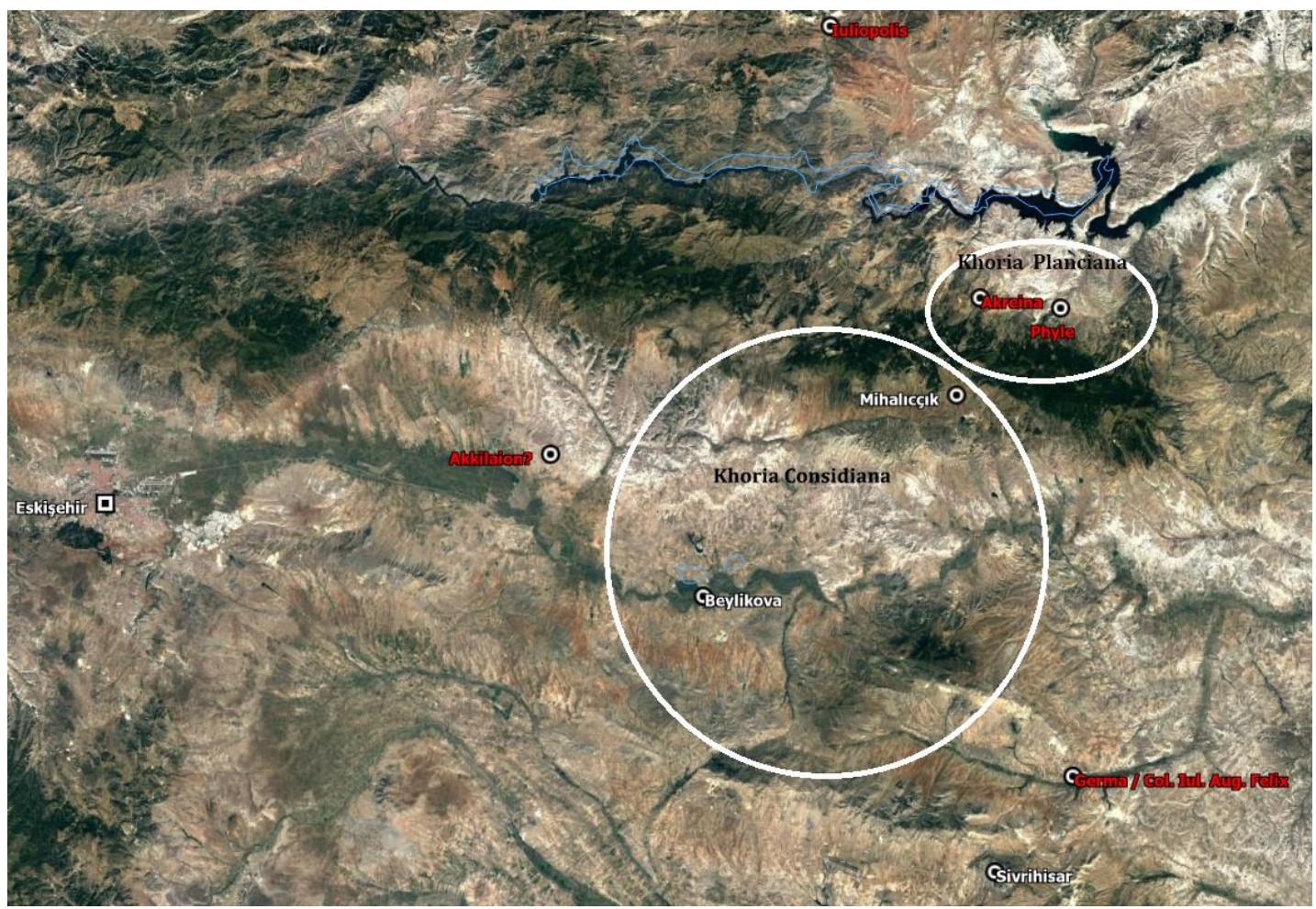

Harita 3. Khoria Considiana ve Khoria Planciana'nın Takribi Sınırlarını Gösteren Harita.

Sonradan imparator mülküne dönüştürülen arazinin ilk sahipliğini belgeleyen isim nasıl tamamlanacak olursa olsun, Aslanapa Ovası'nda İtalik kökenli bir ailenin varlığı ${ }^{64}$ Yukarı Tembris Vadisi'ndeki arazinin tek bir mülkiyetten değil, tersine münferit parsellerden oluştuğunu düşündürmektedir. Bu yöndeki diğer bir kanıt da aslen Italia'daki Fundi kökenli ${ }^{65}$ olup en geç MÖ $60^{\prime}$ ।ı yıllarda Asia Eyaleti'nde, özellikle Akmonia'da ticari faaliyetlerde bulunan ${ }^{66}$, Sestullii ailesinin ${ }^{67}$ Imparatorluk Dönemi'nde Altıntaş Ovası'nda toprak sahibi olduğunu belgeleyen yazıtlardır ${ }^{68}$. Buna göre MS II. yüzyılın sonu veya III. yüzyılın başında Asia Eyaleti'nin başkenti Ephesos'ta

edilmeleri, üyeleri praetor'luktan daha ileriye terfi edememiş tüccar bir ailenin kaderiyle tamamen örtüşmektedir. ayrıca bk. aş. dn. 90; krş. Dalla Rosa 2016, 315 dn. 48.

62 MAMA I 24; Mitchell 1980, 1078-1079.

63 Mitchell 1974, 27-39; Belke 1984, 120; 175-176; 215; Güney 2016, 129; Güney 2018, 56 dn. 11.

64 Cumhuriyet Dönemi'nde Asia eyaletinde İtalik kökenli negotiotores için genel olarak bk. Delplace 1977, 233252; Kirbihler 2007, 19-35.

65 CIL X 6273; krş. Mitchell 1979, 17-18.

66 Cic. Flacc. 34-35; 84-89; 94.

67 Sestulii ailesi için genel olarak bk. Mitchell 1979, 13-22; Drew-Bear 1980, 179-182; Badian 1980; Mitchell 1993 (I), 158; MAMA X 70, 193-194; Thonemann 2013, 30 dn. 116; Türktüzün - Ünan 2017, 39 dn. 10-11.

68 Mitchell 1979, no. 1-4; Waelkens 1986, 94 no. 222 = Cameron 1939, 29 no. 9; Cameron 1939, 29 no. 9a; Kubínska 1987, 422-424 no. 2. 
imparator kültü başrahibi olarak ailenin Imparatorluk Dönemi'ndeki en önemli üyesi olan M. Sestullius Severus Flavianus ${ }^{69}$, babası M. Sestullius Severus için Altıntaş'ta ve Zemme'de görkemli anıtlar yaptırmıştır ${ }^{70}$. Servi Mahallesi'nde, Kütahya Müzesi tarafından 2016 yılı kazılarında ortaya çıkarılan iki yazıt ise M. Sestullius Severus Flavianus'un Kotiaion kenti yurttaşı olduğu bilgisini gün yüzüne çıkarmıştır ${ }^{71}$. Her halükarda Sestullii soyunun bölgede yazıtlar aracılığıyla belgelenen uzun süreli varlığı, üyelerinin bölgenin büyük toprak sahiplerinden olduklarını ve ana mülklerinin ${ }^{72}$ Zemmea'da (Zemme/Çayırbaşı) bulunduğunu işaret etmektedir. Bu veri aynı zamanda Altıntaş Ovası'ndaki imparator arazisinin ovanın tamamını, en azından MS II. yüzyılın sonuna kadar, kapsamadığını da göstermektedir. Buluntu yerleri bilinmemekle birlikte bölge kökenli oldukları kesin olan yazıtların başka toprak sahiplerini de belgelemeleri bu çıkarımı güçlendirmektedir. Philippos ve Claudia Dikaiosyne, patronları P. Claudius Attikos'un arazilerinde çalışırlarken; ${ }^{73}$ Khrysogonos ise L. Aur. Apollinarius Telesphoros'un arazilerini onun azatlı veya köle statüsündeki kâhyası (oíkovó $\mu$ oৎ = vilicus) olarak idare etmiştir ${ }^{74}$. Kütahya Müzesi'nin Servi Mahallesi'nde yürüttüğü kazılar bu alanda da yeni bilgiler sağlamıştır. 2016 yılında bulunan bir yazıt büyük intimalle P. Claudius Attikos'un kızı olan Claudia Secunda'nın Kotiaion kentine ve halkına karşı gösterdiği emsalsiz hayırları ve cömertliği nedeniyle onurlandırılması için çıkarılan Danışma ve Halk meclisleri kararını içermektedir. Buna göre P. Claudius Attikos'un özel arazilerinin Kotiaion teritoryumunda, olasılıkla da Aslanapa Ovası'nda, yer aldığı kesinlik kazanmaktadır. Bütün bu veriler göz önüne alındığında Aslanapa ve Altıntaş ovalarındaki imparator arazilerinin büyük oranda İtalik kökenli ailelerce (Plancii, Sestullii) sahip olunan özel mülkler etrafında geliştiği söylenebilir. Altıntaş Ovasın'daki mermer ocaklarında çalışan işçilerin ihtiyaçları ${ }^{75}$ her iki ovanın hem özel hem de imparator mülkiyeti açısından cazip hale gelmesinde belirleyici olmuştur. Claudius Claudianus'un Kotiaion'u “atlar, sürüler ve Synnada ocaklarındaki (Altıntaş Ovası'ndaki mermer ocakları kastediliyor olmalı) mor damarlı mermer bakımdan zengin bir yer" olarak tanımlaması ${ }^{76}$ bu açıdan anlam kazanmaktadır.

\section{Sonuç}

Roma Cumhuriyet Dönemi'nde Akmonia ve Prymnessos'ta Italik kökenli ailelerin toprak sahibi oldukları bilinirken, ${ }^{77}$ Yukarı Tembris Vadisi'nde bu durum en erken MS II. yüzyılda

69 M. Sestullius Severus Flavianus için ayrıca bk. Campanile 1994, 107-108.

70 Zemme: Mitchell 1979, no. 3 (= MAMA X 193); no. 4 (= IGR IV 610); Altıntaş: MAMA X 70; baba M. Sestulius Severus'un, azatlısı ve sütbabası olan M. Sestullius Pindaros için yaptırdığı mezar için bk. Waelkens 1986, 94 no. 222 = Cameron 1939, 29 no. 9; ailenin Altıntaş Ovası'nda sahip olduğu arazilerde görevli azatlılara ilişkin yazıtlar için bk. Cameron 1939, 29 no. 9a; Mitchell 1979, no. 1-2; Kubínska 1987, 422-424 no. 2.

71 Türktüzün - Ünan 2017, 37-39 no. 2-3.

72 Prymnessos'ta bulunan bir yazıt (MAMA IV 25) ailenin bir kolunun Prymnessos'ta da toprak sahibi olduğunu düşündürmektedir.

73 Waelkens 1986, 95 no. 225; krş. SEG XXIX 1407.

74 Waelkens 1986, 119 no. 283. M. Waelkens (1986, no. 254), aynı bölgeye ait bir başka yazıtta adı geçen Aur. Apollinarius Sabinianus'un Appia yurttaşı L. Aur. Apollinarius Telephoros ile aynı kişi olabileceğini düşünmektedir.

75 Dokimeion mermer ocaklarında çalışan ortalama iş̧̧i sayısı ve bunların yıllık tahmini hububat ihtiyaçları bu konuda aydınlatıcı olmaktadır. A. Dalla Rosa (2016, 320-321), Dokimeion'da ortalama 300-450 arasında kalifiye, 400-650 arasında da vasıfsız işçi çalıştığını ve bunların yıllık hububat ihtiyaçlarının 42.000-63.000 modii arasında olduğunu hesaplamaktadır.

76 Claud. in Eutrop. II. 272: dives equis, felix pecori pretiosaque picto / marmore purpureis, caedit quod Synnada, venis.

77 MÖ 60'Iı yıllarda Akmonia'da ticari faaliyetlerde bulunan Sestullii ailesi dışında Cumhuriyet Dönemi'nde önemli negotiator'lardan L. Egnatius Rufus'un azatlılarının soyundan gelen kişilere ait yazıtlar bilinmektedir: 
belgelenmektedir. Senatus sınıfına mensup birinin veya italik kökenli zengin bir negotiator'un, büyük şehirlerden yoksun ve tarımsal artı ürünün ancak kara yoluyla ve büyük bir nakliye masrafı karşılığında verimli pazarlara ulaştırılabildiği bu kırsal coğrafyada yatırım yapması için belirli bir ekonomik neden bulunmadığından ${ }^{78}$ bu durum hiç de şaşırtıcı değildir. Dolayısıyla kazançlı pazarlardan uzakta konumlanan Phrygia gibi bir bölgede özel şahıs ve imparator mülkiyetindeki arazilerin genişlemesi ancak Dokimeion ve Altıntaş Ovası'ndaki ocaklar gibi büyük üretim ve tüketim merkezlerinin varlığıyla açıklanabilir. Sonuçta imparatorluk çapındaki iddialı imar projelerinin $^{79}$ etkisiyle mermer ekonomisinin giderek gelişmesinden önce Altıntaş ve Aslanapa ovalarındaki tarımsal üretim büyük ölçüde günlük ihtiyaçalara yönelik olmuş gözükmektedir. Mermer endüstrisi yerel sakinlerin ellerindeki arazileri komşu bölgelerde toprak sahibi olan İtalik ailelerin yatıımları açısından cazip hale getirmiş; böylece intiyaç fazlası tarımsal artı üretime uygun olan bölgede büyük arazi sahipliği giderek yaygınlaşmış olmalıdır. Bu gelişmenin ilk aşamasında geniş parseller, çoğu İtalik kökenli olmakla birlikte uzun süredir burada ikamet etmekte olan yerel seçkinlerin eline geçmeye başlamıştır. MS II. yüzyılda Altıntaş Ovasın'daki mermer ocaklarının yakınında Plancii ailesinin Aslanapa Ovası'nda, Sestullii ailesinin ise hem Appia teritoryumundaki Zemmea'da (Zemme/Çayırbaşı) hem de Kotiaion teritoryumunda ve büyük ihtimalle Aslanapa Ovası'nda toprak sahibi olmaları bu yönde güzel örneklerdir.

Bu süreci maaşlarının yanı sıra mermer endüstrisindeki etkin rolleri sayesinde ${ }^{80}$ azatlı procurator'ların sosyal statü edinebilmek için yasal, bazen de yasadışı yollarla kayda değer arazi alımları takip etmiş olmalıdır. ${ }^{81}$ Imparator azatlılarının servetlerini görevli oldukları imparator mülklerinin yakınındaki kentlerde euergesia faaliyetleri için harcadıkları sıkça belgelenmiştir ${ }^{82}$. Büyük ihtimalle Aslanapa Ovası'ndaki imparator mülkünde adiutor tabularii olarak görevli Aurelius Hermes'in (App. 2. 19) vatanı Kotiaion'a karşı yaptığı hizmetler nedeniyle hem eşi lulia Aphrodisia hem de yine bu arazide instrumentarius olarak görev yapan oğlu M. Aur. Hermes (App. 2. 18) Kotiaon'un Danışma ve Halk meclislerinin kararıyla onurlandırılmıştır. Benzer örneklere Yukarı Tembris ve Yukarı Sangarios vadilerindeki diğer yerleşimlerde de ratlanmaktadır. Azatlı procurator Aurelius Aristainetos (App. 1. 21) Synnada Danışma Meclisi tarafından

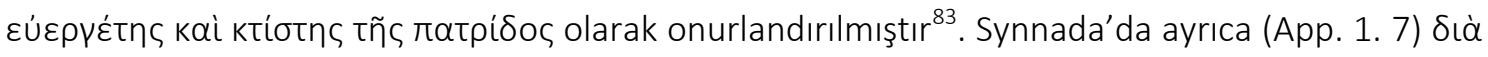

Thonemann 2010, 173-174. Tiberius zamanında Prymnessos'ta ikamet eden negotiatores için bk. Robert 1975,158

78 Cato Maior ekonomik değere sahip bir arazinin tüketim ekononomisinin geliştiği bir kentin veya bir liman ya da taşımacılığa uygun bir nehrin yahut yoğun bir şekilde kullanılan ana güzergahların yakınında bulunmasının önemini vurgulamaktadır; Cato agr. I. 3: oppidum validum prope siet; si aut mare aut amnis, qua naves ambulant, aut via bona celebrisquae.

79 Augustus Dönemi imar projelerinde kullanılan Phrygia mermerleri hakkında bk. yk. s. 427. Hadrianus da Atina'da Hera ve Zeus Panhellenios'un kutsal alanının inşası için Phrygia mermerinden üretilmiş 100 sütun

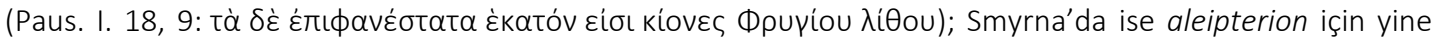
Phrygia mermerinden inşa edilmiş 72 sütun bağışlamıştır (ISmyrna 697 str. 40-41: kéovas عis tò

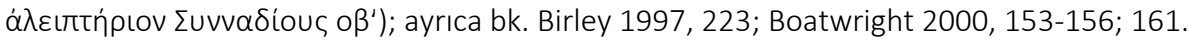

80 İmpartor mülkü mermer ocaklarında görevli azatlıların mermer ticaretinden kazanç elde etmeleri şaşırtıcı değildir. Domitianus ve Nerva zamanlarında procurator lapicidinarum olarak Asia'da görevli Khresimos Tralleis kentine gymnasion'daki caldarium'da duvar kaplaması olarak kullanılmak üzere renkli mermer bağışlamıştır: ITralleis 148 (= CIL III 7146). Khresimos'un Asia'daki görevi için bk. Herrmann 1988, 119-128; Hirt 2004, 115135; Adak - Kadıoğlu 2017, 28.

81 Azatlıların zenginliğine dair bk. Mouritsen 2011, 109-119. Imparator azatlılarının yasadışı para talepleri ve bunlar hakkındaki şikayetler için bk. Haensch 2006, 153-164; krş. Dalla Rosa 2016, 311 dn. 23.

82 Euergesia faaliyetleri için krş. Boulvert 1974, 218-222; Maiuro 2012, 75 dn. 178.

83 IGR IV 703. 


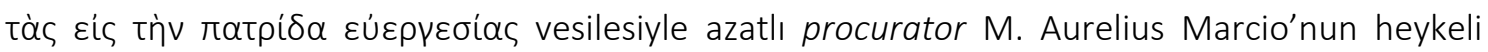

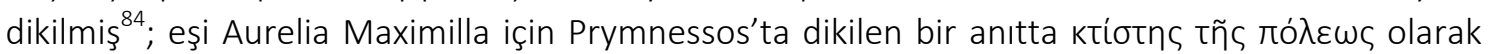
övülmüştür ${ }^{85}$. Aur. Maximilla ayrıca Sangarios Vadisi yerleşimi Trokna'da da onurlandırılmıştır ${ }^{86}$.

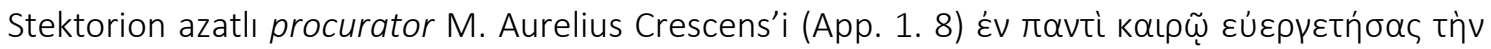
ródıv olması nedeniyle onurlandırmıştır (IGR IV 749). Bu hususta en çarpıcı örnekte ise imparator azatlısı P. Aelius Onesimos (App. 2. 6) vatanı Nakoleia'ya hububat dağıtımı için 200.000 sestertii miras bırakmıştır ${ }^{87}$. Imparator azatılıarının yukarıdaki birkaç örnekteki euergesia faaliyetleri dışında servetlerini nasıl kullandıkları hakkında yeterli veri bulunmamaktadır ${ }^{88}$. Imparator azatılarının şu veya bu şekilde edindikleri servetlerini sosyal statü edinmenin önemli yollarından biri olarak Phrygia'da da toprak alımında kullandıkları düşünülebilir. Augustus zamanında çıkarılan Lex Papia ile servetleri 100.000 sestertii'yi aşan azatlılar (liberti centenarii) arazilerinin, ikiden az çocuk sahibi olmaları durumunda yarısını, iki çocuk sahibi iseler üçte birini patronlarına bırakmak zorundaydılar. Üç veya daha fazla çocuk sahibi azatılıar içinse bu yükümlülük ortadan kalkmaktaydı. ${ }^{89}$. Dolayısıyla imparator azatlılarının bölgede edinmiş olmaları muhtemel arazilerinin en azından bir kısmının bu yolla fiscus'a devri bölgedeki imparator mülklerinin genişlemesinin yollarından biri olmalıdır. İmparator arazilerinin bölgede toprak sahibi olan özel şahıslardan miras veya haciz ${ }^{90}$ yoluyla genişlemesi ise, senatus sınıfı mensuplarının bölgede arazi sahibi olarak belgelenmeye başladıkları ${ }^{91}$ en azından MS II. yüzyılın ortalarından önce daha az başvurulan bir yöntem olmalıdır. İmparatorların doğrudan satın alma yoluna başvurdukları tek örnek ise Domitianus'un eyalette görevli procurator'una Prusa yakınlarında arazi satın alarak bunu filozof Flavius Arkhippos'a hediye etmesini buyurduğu

84

GR IV 704

85 MAMA IV 4

86 IGR IV 546.

87 MAMA V 202. Bu örnek Imparatorluğun doğu eyaletlerinde şimdiye kadar belgelenen en cömert bağışlardan biridir; krş. Zuiderhoek 2009, 167-169; ayrıca bk. Laum 1914, 140-146.

88 Bununla birikte Italia'daki örnekler azatlıların özellikle Ostia gibi önemli limanlarda kreditör olarak ekonomik hayatın önemli aktörleri arasında olduklarını belgelemektedir: Verboven 2011, 88-109.

89 Gai. inst. III. 42: Postea lege Papia aucta sunt iura patronorum, quod ad locupletiores libertos pertinet. cautum est enim ea lege, ut ex bonis eius, qui sestertium centum milibus amplius patrimonium reliquerit et pauciores quam tres liberos habebit, sive is testamento facto sive intestato mortuus erit, virilis pars patrono debeatur; itaque cum unum filium unamue filiam heredem reliquerit libertus, proinde pars dimidia patrono debetur, ac si sine ullo filio filiaue moreretur; cum vero duos duasue heredes reliquerit, tertia pars debetur; si tres relinquat, repellitur patronus. Konu hakkında ayrıca bk. Maiuro 2012, 70-80.

90 Anadolu'da haciz yoluyla elde edilen imparator mülküne dair kesin olan tek veri bulunmaktadır. Buna göre Rubellius Plautus'un (PIR R 115) Asya'nın çeşitli yerlerine dağilmış arazileri (per Asiam avitos agros) MS 62 yılındaki mahkumiyetinin ardından ilkin Octavia'nın, daha sonra da Nero'nun mülkü olmuştur (Tac. ann. XIV. 22; 60). Tiberius zamanında hüküm giyen Considius Aequus $\left(P I R^{2} C 1279\right)$ ve Considius Proculus (PIR ${ }^{2} C$ 1281) ile Choria Considiana'nın ilk sahipleri arasında şu veya bu şekilde bir bağlantı olması durumunda, Choria Considiana'nın da haciz yoluyla imparator mülkiyetine geçtiği düşünülebilir. Atlı sınıfı mensubu Considius Aequus bir praetor hakkında haksız ithamda bulunduğu için MS 21 yılında (Tac. ann. III. 37); praetor'luğa kadar yükselebilmiş senatus sınıfı üyesi Considius Proculus ise MS 33 yılında ihanet suçlamasıyla idam edilmiştir (Tac. ann. VI. 18; V. 8).

91 Akmonia'da Servenii: Halfmann 1979, 56; 102-103 no. 5-5a; Prymnessos’ta Aurelius Sanctus ve eşi Plotina Agrippina: MAMA IV 11; Halfmann 1982, 634 (Aurelius Sanctus Synnada'da da belgelenmiştir: Ramsay 1941, 255-256 no. 249); MS 151-153 yıllarında bir yerde consul suffectus olan A. Iulius Proculus'un eşi Claudia Basilo Synnada kökenlidir: Müller 1980, 457-484; Synnada'da A. Iulius Proculus: Halfmann 1979, 167 no. 82; Aizanoi'da Claudii: Halfmann 1979, 199-200 no. 132-133. 
Bithynia'dandır ${ }^{92}$.

Her halükarda imparator arazileri, genişlemeleri ve daha etkin bir şekilde idare edilebilmeleri için bunların varlığına ihtiyaç duyulduğundan özel mülkiyetin yerini almamış; tersine bununla yanyana gelişmiştir. Epigrafik veriler imparatorların Phrygia'da patrimonium'larını kademeli olarak arttırma politikasını takip ettiklerini ortaya koymaktadır. Bu stratejiyle muhtemelen mermer ocağı endüstrisini desteklemek üzere buralarda çalışan işçilerin ihtiyaçları için gerekli tahıl ve gıdaların etkin bir şekilde üretilmesi amaçlanmış gözükmektedir. Bu durumda imparator mülkü mermer ocakları, bölgedeki imparator arazilerinin kaydadeğer şekilde genişlemesine yol açan en belirleyici etken olmuştur. Aynı zamanda bölge sakinlerinin de mermer ticareti dolayısıyla fiscus'a borçlanmaları (debitor fisci), bunun neticesinde de haciz uygulamasına maruz kalarak patrimonium'un genişlemesine dolaylı olarak katkıda bulunmaları da mümkündür. Sonuçta imparatorların mermer ocağı yakınlarında arazilerini genişletmelerinin doğrudan satın alma dışında farkı yolları söz konusuydu. Bununla birlikte imparator arazilerinin bu şekilde pasif mülk edinme yollarıyla genişleme süreci, Phrygia'da da mülklerin kesintisiz bir bütünlük göstermek yerine farklı noktalara dağılması sonucunu doğurmuştur ${ }^{93}$. Claudius veya Nero'nun azatlısı Phrygia procurator'u Ti. Claudius Aniketos'un Kotiaion'da belgelenen mezar yazıtına ve Flaviuslar Dönemi familia Caesaris üyelerinin bögedeki varlıklarına rağmen, Yukarı Tembris Vadisi'ndeki özel mülklerin yukarıda değinilen çeşitli yollarla imparator arazilerine dönüştürülmeleri en erken Hadrianus zamanından itibaren belgelenmektedir. bütünlük oluşturdukları düşüncesi kabul edilebilir değildir. 


\section{APPENDICES}

App. 1. Phrygia'nın Imparator Azatlısı Procurator'ları

\begin{tabular}{|c|c|c|c|}
\hline Procurator & Unvan & Tarih - Konum & Kaynak \\
\hline 1. Ti. Claudius Aniketos & Aug(usti) lib(ertus) proc. & $\begin{array}{c}\text { Claudius/Nero - } \\
\text { Kotiaion }\end{array}$ & $\begin{array}{l}\text { Türktüzün - Ünan 2017, } \\
\text { no.1. }\end{array}$ \\
\hline 2. Hesperus & 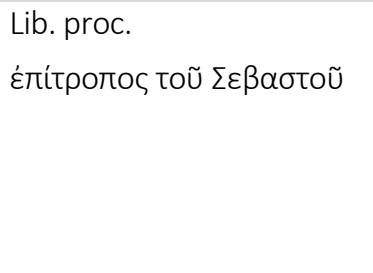 & $\begin{array}{l}\text { Hadrian. - Aizanoi } \\
\text { Leptis Magna }\end{array}$ & $\begin{array}{l}\text { IRT 794d; CIL 3, 355 = OGIS } \\
502 \text { = IGR IV 571; PIR H H 165; } \\
\text { Christol -Drew-Bear 2005: } \\
\text { 199-200; Vitale 2015, } 37 \text { no. } \\
\text { 1A; Dalla Rosa 2016, } 324 \text { no. } \\
\text { 7. }\end{array}$ \\
\hline 3. September & Proc. Aug. lib. & Hadrian. - Kotiaion & $\begin{array}{l}\text { MAMA X 255, } 259=\text { CIL III } \\
\text { 7004; Weaver, Repertorium } \\
414 \text { no. 2951; Dalla Rosa } \\
2016,325 \text { no. } 21 \text { (farklı } \\
\text { tamamlama önerisi için bkz. } \\
\text { AE 1993, 1511; krş. Vitale } \\
\text { 2015, 37). }\end{array}$ \\
\hline 4. [Statilius] Marcianus? & 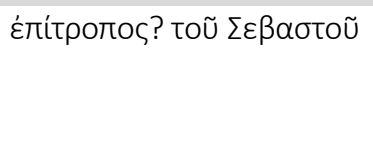 & Hadrian. - Laodikeia & $\begin{array}{l}\text { IGR IV } 856=\text { CIG } 3939= \\
\text { ILaodikeia 43; Vitale 2015, } \\
37 \text { no. } 3 \text { A; } 34 \text { dn. } 7 .\end{array}$ \\
\hline 5. Irenaios & Aug. lib. proc. & $\begin{array}{c}\text { MS 125/126 - } \\
\text { Metropolis (Tatarlı) } \\
\text { MS } 136 \text { - Roma }\end{array}$ & $\begin{array}{l}\text { CIL III 12237; ILS 8716a = } \\
\text { Fant 1989, } 252 \text { no.1; ILS } \\
\text { 8716b = Fant 1989, } 253 \text { no. } \\
\text { 2; Hirt 2010, App. 115-116; } \\
\text { Weaver, Repertorium } 263 \\
\text { no. 1611; Dalla Rosa 2016, } \\
324 \text { no. 10-11. }\end{array}$ \\
\hline 6. T. Aelius (Quintianus) & $\begin{array}{l}\text { Aug. lib. verna proc. } \\
\text { proc. provinciae Phrygiae }\end{array}$ & Ant. Pius - Synnada & $\begin{array}{l}\text { MAMA IV 55; Hirt 2010, } 114 \\
\text { dn. 39; Weaver, Repertorium } \\
298 \text { no. } 1831 \text {; Thonemann } \\
2011,113 \text { dn. 38; Dalla Rosa } \\
\text { 2016, } 324 \text { no. } 14 .\end{array}$ \\
\hline 7. M. Aur. Marcio & 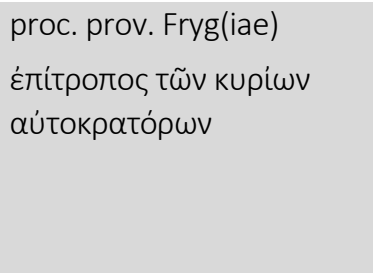 & $\begin{array}{l}\text { M. Aur. - Trokna(da) } \\
\text { Prymnessos } \\
\text { Synnada }\end{array}$ & $\begin{array}{l}\text { CIL III 348; IGR IV 676, 704; } \\
\text { MAMA IV 4; PIR A 1551; IGR } \\
\text { IV 704; Vitale 2015, } 37 \text { no. } \\
\text { 4A; Weaver, Repertorium } \\
344 \text { no. 2139; Dalla Rosa } \\
\text { 2016, } 324 \text { no. 15-18. }\end{array}$ \\
\hline 8. M. Aur. Crescens & غ́ті́тротос Фрuүías & $\begin{array}{l}\text { M. Aur./Commodus - } \\
\text { Stektorion }\end{array}$ & $\begin{array}{l}\text { IGR IV 749; PIR }{ }^{2} \text { A 1489; Vita- } \\
\text { le 2015, } 37 \text { no. 5A; Weaver, } \\
\text { Repertorium } 318 \text { no. 1897; } \\
\text { Dalla Rosa 2016, } 325 \text { no. } 19 .\end{array}$ \\
\hline 9. Maro & Aug. lib. proc. & MS 194 - Trokna(da) & $\begin{array}{l}\text { Christol - Drew-Bear 1991, } \\
\text { no. 1-2; Hirt 2010, App 302- } \\
\text { 303. }\end{array}$ \\
\hline 10. T. Aelius Aminatos & Aug. lib. proc. & MS II. yüzyıl - Laodicea & CIL III 287; MAMA I 21; \\
\hline
\end{tabular}




\begin{tabular}{|c|c|c|c|}
\hline & & Combusta & $\begin{array}{l}\text { Weaver, Repertorium 229- } \\
230 \text { no. } 1426 .\end{array}$ \\
\hline 11. M. Ulpius Marianus & Aug. lib. proc. & MS II. yüzyıl - Synnada & $\begin{array}{l}\text { CIL III 7046, 7048; Weaver, } \\
\text { Repertorium } 206 \text { no. } 1268 \text {; } \\
\text { Dalla Rosa } 2016 \text {, } 324 \text { no. } 6 .\end{array}$ \\
\hline 12. Saturninus Aponius & غ́літротоৎ & MS II. yüzyıl? - Aizanoi & $\begin{array}{l}\text { MAMA IX } 180 \text { P66; Vitale } \\
\text { 2015, } 34 \text { dn.7. }\end{array}$ \\
\hline 13. Lolliu[s Lolli?]anus & 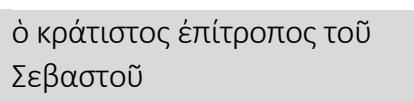 & MS II. yüzyıl - Akmonia & $\begin{array}{l}\text { IGR IV, 652; PIR L } 316 \\
\text { Pflaum 1960, } 1102 .\end{array}$ \\
\hline 14. Aur. Faustinus & 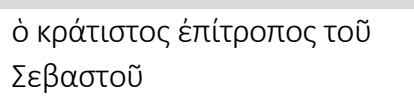 & MS II. yüzyıl - Akmonia & $\begin{array}{l}\text { MAMA VI 378; Vitale 2015, } \\
34 \text { dn.7. }\end{array}$ \\
\hline 15. Zotikos & غ́пітротоৎ & $\begin{array}{l}\text { MS II. yüzyıl - } \\
\text { Eumeneia }\end{array}$ & $\begin{array}{l}\text { IGR IV 727; Vitale 2015, } 34 \\
\text { dn.7. }\end{array}$ \\
\hline 16. Anoymos & 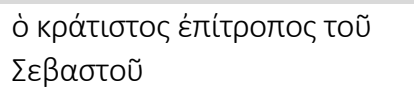 & $\begin{array}{l}\text { MS II. yüzyıl - } \\
\text { Hierapolis }\end{array}$ & $\begin{array}{l}\text { Judeich } 1898,87 \text { no. } 42 ; \\
\text { Vitale } 2015,34 \text { dn. } 7 .\end{array}$ \\
\hline 17. Anonymos & Proc. Augg. & MS 205/208 - Tymion & $\begin{array}{l}\text { Hauken et al. } 2003=A E \\
\text { 2003, 1690; Vitale 2015, } 37 \\
\text { no. } 8 \text { A. }\end{array}$ \\
\hline 18. Aur. Epity[nkhanos] & [sub cu]ra Aur. Epity[nchani'] & MS 206 - Bacakale? & $\begin{array}{l}\text { Christol - Drew-Bear 1991, } \\
119 \text { dn. 31; } 171 \text { dn. 223; Hirt } \\
\text { 2010, 113-114; App. } 437 .\end{array}$ \\
\hline 19. Kristobulos & غ́пітропоৎ & MS 207/208 - Kibyra & $\begin{array}{l}\text { SEG XLVIII 1585a; Vitale } \\
\text { 2015, } 37 \text { no. 7A. }\end{array}$ \\
\hline 20. Aur. Elpidephoros & 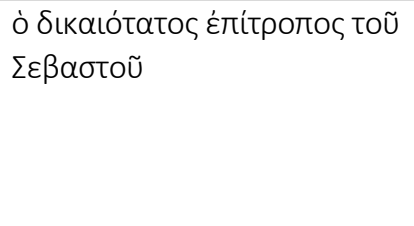 & Sept./Car. - Synnada & $\begin{array}{l}\text { AE 2006, } 1430 \text { = SEG LVI } \\
\text { 1689; PIR A 1497; Vitale } \\
\text { 2015, } 37 \text { no. 6A =? Weaver, } \\
\text { Repertorium } 335 \text { no. } 2058 ; \\
\text { Dalla Rosa 2016, } 325 \text { no. } 23 .\end{array}$ \\
\hline 21. Aur. Aristainetos & 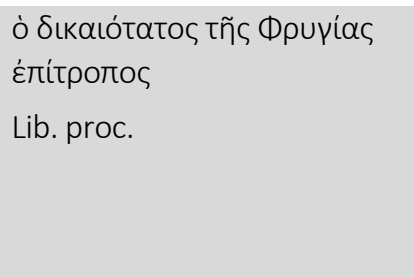 & $\begin{array}{c}\text { MS 212-235 - } \\
\text { Synnada / Pergamon }\end{array}$ & $\begin{array}{l}\text { MAMA IV 63; IGR IV 703; } \\
\text { PIR A A 1497; Vitale 2015, } 37 \\
\text { no. } 9 A=\text { ? IPergamon III 14- } \\
15 \text { ve AE 1933, 281'teki } \\
\text { Aristainetos; krş. Dalla Rosa } \\
\text { 2016, } 325 \text { no. 24-25. }\end{array}$ \\
\hline 22. $[\ldots] \mathrm{s}$ & Lib. proc. & $\begin{array}{l}\text { MS 212-235 - } \\
\text { Pergamon }\end{array}$ & $\begin{array}{l}A E \text { 1933, 281; Weaver, } \\
\text { Repertorium } 374 \text { no. } 2529 .\end{array}$ \\
\hline 23. Aur. Philokyrios & 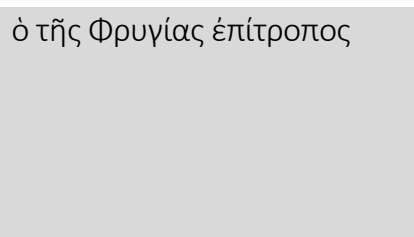 & $\begin{array}{c}\text { MS } 213 \text { - Takina } \\
\text { Prymnessos }\end{array}$ & $\begin{array}{l}\text { SEG XIII 625; XXXVII 1186; } \\
\text { Vitale 2015, } 37 \text { no. } 10 \text {; } \\
\text { Weaver, Repertorium } 353 \\
\text { no. } 2224 a ; \text { Dalla Rosa 2016, } \\
325 \text { no. } 20 \text {. }\end{array}$ \\
\hline 24. L. Didius Marinus & Lib. proc. & MS 215 - Pergamon & $\begin{array}{l}\text { IPergamon III 14-15; AE } \\
\text { 1933, 281-282. }\end{array}$ \\
\hline 25. Aur. Tacitus & Lib. proc. & MS 215 - Pergamon & $\begin{array}{l}A E \text { 1933, 282; Weaver, } \\
\text { Repertorium } 365 \text { no. } 2433 .\end{array}$ \\
\hline 26. Aur. Threptos & Proc. & MS 217-237 - Euladra & SEG XIII 625; Vitale 2015, 37 \\
\hline
\end{tabular}


no. 11A; Weaver, Repertorium 366 no. 2447a; Dalla Rosa 2016, 325 no. 20.

\begin{tabular}{|c|c|c|c|}
\hline 27. Novellius & Proc. & MS 237 - Euladra & $\begin{array}{l}\text { SEG XIII 625; Vitale 2015, } 37 \\
\text { no. } 12 \text { A; Weaver, Reper- } \\
\text { torium } 349 \text { no. } 2185 \text { a; Dalla } \\
\text { Rosa } 2016,325 \text { no. } 20 .\end{array}$ \\
\hline 28. Aur. Theon & 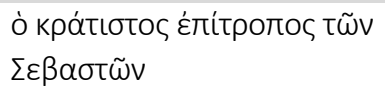 & MS 244/249 - Aizanoi & $\begin{array}{l}\text { MAMA IX } 17 \text { Vitale 2015, } 37 \\
\text { no. } 13 \text { A; } 34 \text { dn. } 7 .\end{array}$ \\
\hline
\end{tabular}

App. 2. Phrygia'da İmparator Mülklerinde Görevli Familia Caesaris Üyeleri

\begin{tabular}{|c|c|c|c|}
\hline Görevli & Görev & Tarih - Konum & Kaynak \\
\hline 1. Hyakinthos & Neronis Caes. Aug. tabularius & Nero - Synnada & $\begin{array}{l}\text { CIL III } 7047=\text { IGR IV } 710= \\
\text { MAMA IV 53; Weaver, } \\
\text { Repertorium } 458 \text { no. } 3472 .\end{array}$ \\
\hline 2. T. Flavius Helios & 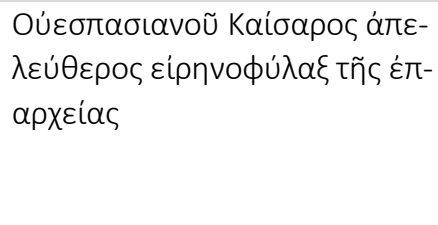 & MS 79 - Appia & $\begin{array}{l}\text { Drew Bear - Naour 1990, } \\
\text { 1967-1981 no. 15-16; Wea- } \\
\text { ver, Repertorium 156-157 } \\
\text { no. 887; Dalla Rosa 2016, } \\
323 \text { no. } 2 \text {. }\end{array}$ \\
\hline 3. Ti. Cl. Onesimos & Aug. lib. & Flav. - Synnada & $\begin{array}{l}\text { Dalla Rosa 2016, } 324 \text { no. 3; } \\
\text { Pensabene 2014, } 31 \text { fig. } 17 .\end{array}$ \\
\hline 4. Saturninus & Caes. serv. & Flav. - Dokimeion & $\begin{array}{l}\text { AE 1986, 674; Weaver, } \\
\text { Repertorium } 474 \text { no. } 3639 ; \\
\text { Dalla Rosa 2016, } 324 \text { no. } 5 .\end{array}$ \\
\hline 5. [...]us Priamos & Aug. lib. & Flav. - Synnada & Dalla Rosa 2016, 323 no. 1. \\
\hline 6. P. Aelius Onesimos & Aug. lib. & Hadrian. - Nakoleia & $\begin{array}{l}\text { MAMA V 202; Weaver, } \\
\text { Repertorium } 270 \text { no. } 1661 ; \\
\text { Dalla Rosa 2016, } 324 \text { no. } 9 .\end{array}$ \\
\hline 7. Olympos & 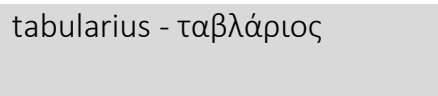 & Hadrian. - Synnada & $\begin{array}{l}\text { Drew-Bear 1978, } 12 \text { no. 5; } \\
\text { Waelkens 1986, } 200 \text { no. } 496 .\end{array}$ \\
\hline 8. M. Aur. Victorinus & 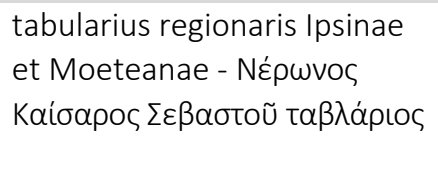 & $\begin{array}{l}\text { MS 161-169- } \\
\text { Prymnessos }\end{array}$ & $\begin{array}{l}\text { Ballance 1969, 143; Wea- } \\
\text { ver, Repertorium } 369 \text { no. } \\
\text { 2478; Dalla Rosa 2016, } 325 \\
\text { no. } 22 \text {. }\end{array}$ \\
\hline 9. T. Ael. Aur. Niger & 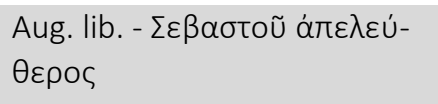 & Anton. Pius - Nakoleia & $\begin{array}{l}\text { IGR IV 544; Weaver, Reper- } \\
\text { torium } 269 \text { no. } 1653 .\end{array}$ \\
\hline 10. Niger Minor & 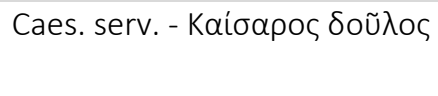 & Anton. Pius - Nakoleia & $\begin{array}{l}\text { IGR IV 543; Weaver, Reper- } \\
\text { torium } 269 \text { no. } 1653 \text {. }\end{array}$ \\
\hline 11. Krateros & Caesaris servus verna & M. Aur. - Nakoleia & $\begin{array}{l}\text { MAMA V 197; Weaver, } \\
\text { Repertorium } 501 \text { no. } 3913 .\end{array}$ \\
\hline 12. M. Aur. Senecianus & ex tabulario & $\begin{array}{l}\text { MS } 176-180- \\
\text { Trokna(da) }\end{array}$ & $\begin{array}{l}\text { CIL III 348; Weaver, } \\
\text { Repertorium } 361 \text { no. } 2299 .\end{array}$ \\
\hline 13. Khrestos & 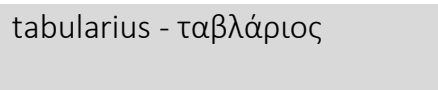 & M. Aur. - Euladra & $\begin{array}{l}\text { IGR IV 679; Weaver, } \\
\text { Repertorium } 315 \text { no. } 1874 .\end{array}$ \\
\hline
\end{tabular}




\begin{tabular}{|c|c|c|c|}
\hline 14. Dionysios & Aug. dispensator & MS II. yüzyıl - Appia & $\begin{array}{l}\text { CIL III 7002; Weaver, Reper- } \\
\text { torium } 502 \text { no. } 3924 .\end{array}$ \\
\hline 15. M. Ulpius Paedero & Mariani lib. & $\begin{array}{l}\text { MS II. yüzyıl - } \\
\text { Synnada }\end{array}$ & $\begin{array}{l}\text { CIL III 7048; Weaver, Reper- } \\
\text { torium } 211 \text { no. } 1298 .\end{array}$ \\
\hline 16. Fl? Amiantos & Aug. lib. a commentariis & $\begin{array}{l}\text { MS II. yüzyıl - } \\
\text { Synnada }\end{array}$ & $\begin{array}{l}\text { CIL III 7045; MAMA IV 62; } \\
\text { Weaver, Repertorium } 135 \\
\text { no. 748; Dalla Rosa 2016, } \\
324 \text { no. } 12 \text {. }\end{array}$ \\
\hline 17. M. Aur. Paullus & 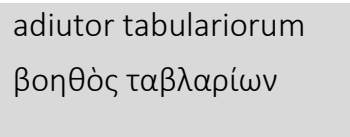 & $\begin{array}{l}\text { MS III. yüzyıl - } \\
\text { Synnada }\end{array}$ & $\begin{array}{l}\text { Drew-Bear 1978, 10-12 no. 4; } \\
\text { Weaver, Repertorium } 351 \text { no. } \\
2206 .\end{array}$ \\
\hline 18. M. Aur. Hermes & 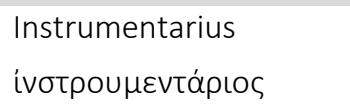 & $\begin{array}{l}\text { MS III. yüzyıl - } \\
\text { Kotiaion }\end{array}$ & $\begin{array}{l}\text { Türktüzün - Ünan 2017, } 41 \\
\text { no. } 6 .\end{array}$ \\
\hline 19. Aur. Hermes & 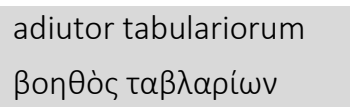 & $\begin{array}{l}\text { MS III. yüzyıl - } \\
\text { Kotiaion }\end{array}$ & $\begin{array}{l}\text { Türktüzün - Ünan 2017, } 43- \\
44 \text { no. 6, } 9 .\end{array}$ \\
\hline 20. Proculus & Augg. [lib. veya verna] & MS III. yüzyıl - Appia & MAMA X 136. \\
\hline
\end{tabular}

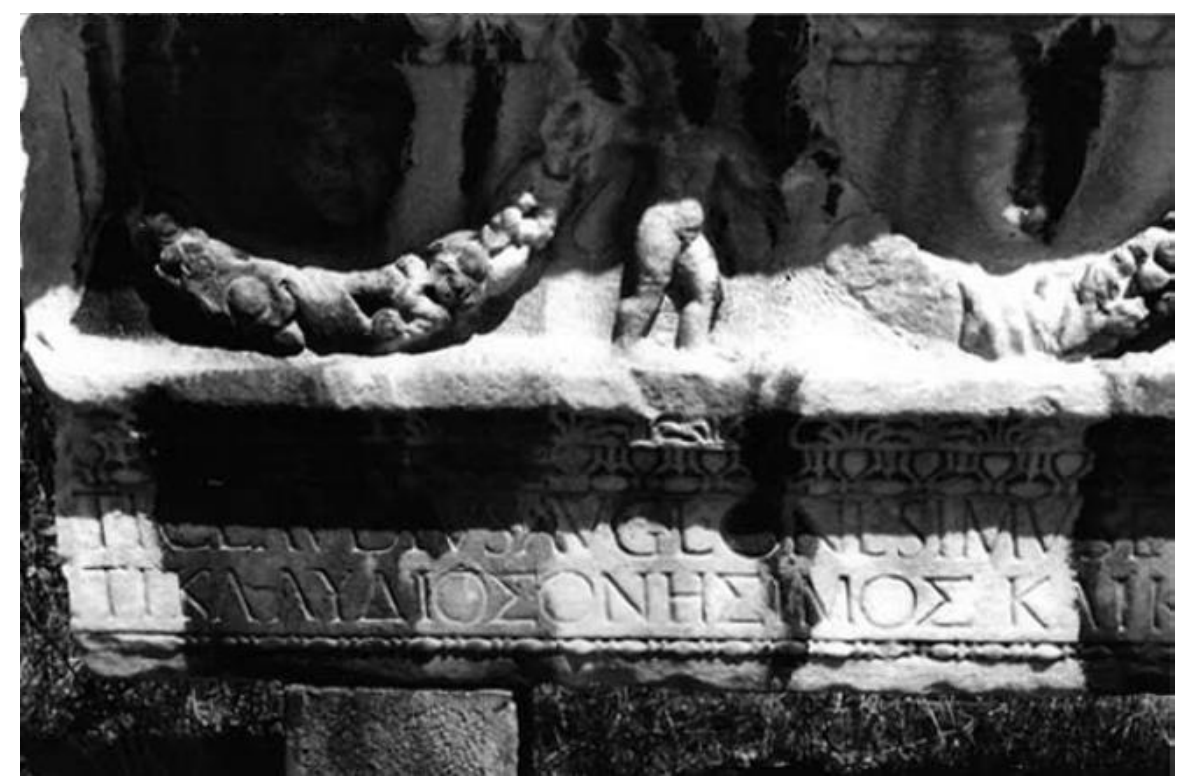

Fig. 1. Ti. Claudius Onesimos'un Mezar Anıtı (Pensabene 2013, 31 fig. 17'den). 


\section{BIBBLIYOGRAFYA}

Adak - Kadıoğlu 2017

$A E$

AJA

AJPh

AMS

Anderson 1897

Anderson 1937

ANRW

AS

Badian 1980

Ballance 1969

$B E$

Beaudouin 1899

Belke 1984

Belke - Mersich 1990

Birley 1997

Boatwright 2000

Boulvert 1970

Boulvert 1974

Bowersock 1995

Broughton 1934

Broughton 1938

Brunt 1990

Buckler et al. 1925

Buckler et al. 1928

Cameron 1939

Campanile 1994

Christol - Drew-Bear 1982

Christol - Drew-Bear 1986

Christol - Drew-Bear 1991

Christol - Drew-Bear 2005
M. Adak - M. Kadıoğlu, "Die Steinbrüche von Teos und «Marmor Luculleum»". Philia III (2017) 1-43.

L'année épigraphique. Paris 1888-.

American Journal of Archaeology. Boston 1897-.

American Journal of Philology. Baltimore 1880-

Asia Minor Studien. Bonn 1990-.

J. G. C. Anderson, “A Summer in Phrygia I" JHSXVII (1897) 396-424.

J. G. C. Anderson, "An Imperial Estate in Galatia". JRS XXVII (1937) 18-21.

Ed. H. Temporini - W. Haase, Aufstieg und Niedergang der römischen Welt. Geschichte und Kultur Roms im Spiegel der neueren Forschung. Berlin - New York 1972-.

Anatolian Studies, Journal of the British School at Ankara. Londra 1951-.

E. Badian, "A fundus at Fundi". AJPh Cl (1980) 470-482.

M. H. Ballance, "Regio Ipsina et Moeteana". AS XIX (1969) 143-146.

Bulletin épigraphique. Paris 1888-.

É. Beaudouin, Les grands domaines dans l'empire romain d'après des travaux récents. Paris 1899.

K. Belke, Tabula Imperii Byzantini 4: Galatien und Lykaonien (Denkschriften ÖAW, phil.-hist. KI. 172). Viyana 1984.

K. Belke - N. Mersich, Tabula Imperii Byzantini 7: Phrygien und Pisidien (Denkschriften ÖAW, phil.-hist. Kl. 211). Viyana 1990.

A. R. Birley, Hadrian: The Restless Emperor. Londra 1997.

M. T. Boatwright, Hadrian and the Cities of the Roman Empire. Princeton 2000.

G. Boulvert, Esclaves et affranchis impériaux sous le Haut-Empire romain. Rôle politique et administratif. Napoli 1970.

G. Boulvert, Domestique et fonctionnaire sous le Haut-Empire romain : Ia condition de l'affranchi et de l'esclave du prince. Paris 1974.

G. W. Bowersock, Martyrdom and Rome. Cambridge 1995.

T. R. S. Broughton, "Roman Landholding in Asia Minor". TAPA LXV (1934) 207239.

T. R. S. Broughton, "Roman Asia Minor". Ed. T. Frank, An Economic Survey of Ancient Rome IV. Baltimore (1938) 499-918.

P. A. Brunt, "Procuratorial Jurisdiction". Ed. P. A. Brunt, Roman Imperial Themes. Oxford (1990) 163-187.

W. H. Buckler - W. M. Calder - C. W. M. Cox, "Asia Minor, 1924: II. Monuments from Cotiaeum". JRS XV (1925) 141-175.

W. H. Buckler - W. M. Calder - C. W. M. Cox, “Asia Minor, 1924: V. Monuments from the Upper Tembris Valley". JRS XVIII (1928) 21-40.

A. Cameron, "Opertós and Related Terms in the Inscriptions of Asia Minor". Eds. W. M. Calder - J. Keil, Anatolian Studies presented to William Hepburn Buckler. Aberdeen (1939) 27-62.

D. Campanile, Sacerdoti del Koinon d'Asia (I sec. a. C. - III sec. d. C.). Pisa 1994.

M. Christol - T. Drew-Bear, Travaux et recherches en Turquie II. Collectanea Turcica II. İstanbul (1982) 23-42.

M. Christol - T. Drew-Bear, "Documents latins du Phrygie". Tyche I (1986) 41-87.

M. Christol - T. Drew-Bear, "Les carrières de Dokimeion à l'époque severienne". EA LIII (1991) 113-174.

M. Christol - T. Drew-Bear, "De Lepcis Magna à Aizanoi: Hesperus procurateur de Phrygie et l'administration des carrières de marbre". Eds. J. Desmulliez - C. Hoët-van Cauwenberghe, Le monde romain à travers l'épigraphie: méthodes et pratiques. Actes du XXIVe Colloque international de Lille, 8-10 November 2001. Lille (2005) 189-216. 
CIG

CIL

Crawford 1976

Dalla Rosa 2016

Delplace 1977

Drew-Bear 1978

Drew-Bear 1980

Drew-Bear - Eck 1976

Drew-Bear - Naour 1990

$E A$

Fant 1989

French 1991

Gruen 1974

Güney 2016

Güney 2018

Haensch 1997

Haensch 2006

Halfmann 1979

Halfmann 1982

Hauken et al. 2003

Herrmann 1988

Herrmann 1990

Hirschfeld 1902

Hirt 2004
Ed. A. Böckh, Corpus Inscriptionum Graecarum I-IV. Berlin 1828-1877. Corpus Inscriptionum Latinarum. Berlin 1863-.

D. J. Crawford, "Imperial Estates". Ed. M. Finley, Studies in Roman Property. Cambridge (1976) 35-70.

A. Dalla Rosa, "From Exploitation to Integration. Imperial Quarries, Estates and Freedmen, and the Integration of Rural Phrygia". Studii Hellenistici XXX (2016) 305-330.

C. Delplace, "Publicains, trafiquants et financiers dans les provinces d'Asie Mineure sous la République". Ktèma II (1977) 233-252.

T. Drew-Bear, Nouvelles inscriptions de Phrygie (Studia Amstelodamensia ad epigraphicam, ius antiquum et papyrologicam pertinentia: 16). Zutphen 1978.

T. Drew-Bear, "Recherches épigraphiques et philologiques". REA LXXXII (1980) 155-182.

T. Drew-Bear - W. Eck, "Kaiser-, Militär- und Steinbruchinschriften aus Phrygien". Chiron VI (1976) 289-318.

T. Drew-Bear - C. Naour, "Divinités de Phrygie". ANRW II.18.3 (1990) 19072044.

Epigraphica Anatolica. Zeitschrift für Epigraphik und historische Geographie Anatoliens. Bonn 1983-.

J. C. Fant, Cavum Antrum Phrygiae. The Organization and Operations of the Roman Imperial Marble Quarries in Phrygia (BAR International Series 482). Oxford 1989

D. H. French, Sites and Inscriptions from Phrygia, Pisidia and Pamphylia. EA XVII (1991) 51-68

E. S. Gruen, The Last Generation of the Roman Republic. Berkeley - Los Angeles - Londra 1974.

H. Güney, "New inscriptions from the Choria Considiana: Çalçak Roman Necropolis" AS LXVI (2016) 125-139.

H. Güney, "New Epigraphic Documents from Northeast Phrygia". Philia IV (2018) 55-66.

R. Haensch, Capita provinciarum. Statthaltersitze und Provinzialverwaltung in der römischen Kaiserzeit. Mainz 1997.

R. Haensch, "Von den Augusti liberti zu den Caesariani". Ed. A. Kolb, Herrschaftsstrukturen und Herrschaftspraxis. Konzepte, Prinzipien und Strategien der Administration im römischen Kaiserreich. Akten der Tagung an der Universität Zürich, 18-20.10.2004. Berlin (2006) 153-164.

H. Halfmann, Die Senatoren aus dem östlichen Teil des Imperium Romanum bis zum Ende des 2. Jahrhunderts n. Chr.. Göttingen 1979.

H. Halfmann, Die Senatoren aus den Kleinasiatischen Provinzen des römischen Reiches vom 1-3. Jahrhundert (Asia, Pontus-Bithynia, Lycia-Pamphylia, Galatia, Cappadocia, Cilicia)". Epigrafia e ordine senatorio. Atti del colloquio internazionale AIEGL. Rom, 14-20 maggio 1981. Roma (1982) 603-649.

T. Hauken - C. Tanrıver - K. Akbıyıkoğlu, "A New Inscription from Phrygia. A Rescript of Septimius Severus and Caracalla to the coloni of the Imperial Estate at Tymion". EA XXXVI (2003) 33-44.

P. Herrmann, "Chresimus, procurator lapicidinarum. Zur Verwaltung der kaiserlichen Steinbrüche in der Provinz Asia". Tyche III (1988) 119-128.

P. Herrmann, Hilferufe aus römischen Provinzen. Ein Aspekt der Krise des römischen Reiches im 3. Jhdt. n. Chr.. Hamburg 1990.

O. Hirschfeld, "Der Grundbesitz der römischen Kaiser in den ersten drei Jahrhunderten" Klio II (1902) 45-72; 284-315.

A. M. Hirt, "Chresimus, procurator a marmoribus und der Strassenbau. Überlegungen zu Logistik und Transportwesen kaiserlicher Steinbrüche". Ed. R. Frei-Stolba, Siedlung und Verkehr im römischen Reich. Römerstraßen zwischen 
Hirt 2010

$J D A /$

$J \ddot{A A I}$

$J R S$

Judeich 1898

IEphesos

IGR

IK

ILaodikeia

ILS

IPergamon

IRT

ISmyrna

ITralleis

Kantor 2013

Kehoe 2007

Kirbihler 2007

Kubínska 1987

Laum 1914

Maiuro 2012

MAMA I

MAMA IV

MAMA VI

MAMA VII

MAMA IX

MAMAX
Herrschaftssicherung und Landschaftsprägung. Akten des Internationalen Kolloquiums zu Ehren von H. E. Herzig. Bern (2004) 115-134.

A. M. Hirt, Imperial Mines and Quarries in the Roman World: Organizational Aspects 27 BC - AD 235. Oxford 2010.

Jahrbuch des des Deutschen Archäologischen Instituts. Berlin 1886-.

Jahreshefte des Österreichischen Archäologischen Instituts in Wien. Viyana 1898-

Journal of Roman Studies. Londra 1911-.

W. Judeich, "Die Inschriften". Eds. C. Humann - C. Cichorius - W. Judeich - F. Winter, Altertümer von Hierapolis. Berlin (1898) 67-202.

H. Engelmann - D. Knibbe - R. Merkelbach, IK 13: Die Inschriften von Ephesos [600-1000]. Bonn 1980. C. Börker - R. Merkelbach, IK 15: Die Inschriften von Ephesos [1446-2000]. Bonn 1980. R. Merkelbach - J. Nollé, IK 16: Die Inschriften von Ephesos [2001-2958]. Bonn 1980. R. Meriç - R. Merkelbach - J. Nollé - S. Şahin, IK 17.1: Die Inschriften von Ephesos [3001-3500]. Bonn 1980.

Ed. R. Cagnat, Inscriptiones Graecae ad res Romanas pertinentes I-IV. Paris 1906-1927.

Inschriften griechischer Städte aus Kleinasien. Bonn 1972-.

T. Corsten, IK 49: Die Inschriften von Laodikeia am Lykos. Teil I. Die Inschriften. Bonn 1997.

Ed. H. Dessau, Inscriptiones Latinae Selectae I-III. Berlin 1892-1916.

Ed. M. Fränkel, Die Inschriften von Pergamon (Altertümer von Pergamon, 8,12). Berlin 1890-1895.

Ed. C. Habicht, Die Inschriften des Asklepieions. Mit einem Beitrag von Michael Wörrle (Altertümer von Pergamon 8,3). Berlin 1969.

J. M. Reynolds - J. B. Ward-Perkins, The Inscriptions of Roman Tripolitania. Rome 1952.

G. Petzt, IK 24.1: Die Inschriften von Smyrna II.1. Bonn 1987.

F. B. Poljakov, IK 36, 1: Inschriften von Tralleis und Nysa. Bonn 1989.

G. Kantor, "Law in Roman Phrygia: Rules and Jurisdictions". Ed. P. Thonemann, Roman Phrygia: Culture and Society. Cambridge (2013) 143-166.

D. P. Kehoe, Law and the Rural Economy in the Roman Empire. Ann Arbor 2007.

F. Kirbihler, "Die Italiker in Kleinasien, mit besonderer Berücksichtigung von Ephesos (133 v. Chr. - 1. Jh. n. Chr)". Ed. M. Meyer, Neue Zeiten, neue Sitten: zu Rezeption und Integration römischen und italischen Kulturguts in Kleinasien. Viyana (2007) 19-35.

J. Kubínska, "Deux inscriptions du Musée National de Varsovie". BCH CXI (1987) 419-424.

B. Laum, Stiftungen in der griechischen und römischen Antike. Ein Beitrag zur antiken Kulturgeschichte. Leipzig 1914.

M. Maiuro, Res Caesaris : ricerche sulla proprietà imperiale nel principato. Bari 2012.

W. M. Calder, Monumenta Asiae Minoris Antiqua, vol. I. Manchester 1928.

W. H. Buckler - W. M. Calder - W. K. C. Guthrie, Monumenta Asiae Minoris Antiqua, vol. IV: Monuments and Documents from Eastern Asia and Western Galatia. Manchester 1933.

W. H. Buckler - W. M. Calder, Monumenta Asiae Minoris Antiqua, vol. VI: Monuments and Documents from Phrygia and Caria. Manchester 1939.

W. M. Calder, Monumenta Asiae Minoris Antiqua, vol. VII: Monuments from Eastern Phrygia. Manchester 1956.

B. Levick - S. Mitchell - J. Potter - M. Waelkens, Monumenta Asiae Minoris Antiqua, vol. IX: Monuments from the Aezanitis recorded by C. W. M. CoX, A. Cameron, and J. Cullen (JRS Monographs no. 4). Londra 1988.

B. Levick - S. Mitchell - J. Potter - M. Waelkens, Monumenta Asiae Minoris 
Millar 1977

Mitchell 1974

Mitchell 1979

Mitchell 1980

Mitchell 1982

Mitchell 1993

Mitchell 1999

Mouritsen 2011

Müller 1980

OGIS

Pensabene 2014

Pelham 1890

Pflaum 1960

$P I R^{2}$

Potter 1998

Ramsay 1941

REA

Robert 1975

Rostovtzeff 1957

Röder 1971

Schulten 1896

SEG

Strubbe 1975

Tabbarnee - Lampe 2008

Takmer 2018

TAPA

Thonemann 2010

Thonemann 2011

Thonemann 2013
Antiqua, vol. X: Monuments from the Upper Tembris Valley, Cotiaeum, Cadi, Synaus, Ancyra, and Tiberiopolis recorded by C. W. M. Cox, A. Cameron, and J. Cullen (JRS Monographs no. 7). Londra 1993.

F. Millar, The Emperor in the Roman World (31 BC-AD 337). Londra 1977.

S. Mitchell, "The Plancii in Asia Minor". JRS LXIV (1974) 27-39.

S. Mitchell, "R.E.C.A.M. Notes and Studies No. 5: A Roman Family in Phrygia". AS XXIX (1979) 13-22.

S. Mitchell, "Population and the Land in Roman Galatia". ANRW II.7.2 (1980) 1053-1081.

S. Mitchell, Regional Epigraphic Catalogues of Asia Minor, vol. II: The Ankara District. The Inscriptions of North Galatia (British Archaeological Reports, International Series, 135). Oxford 1982.

S. Mitchell, Anatolia: Land, Men and Gods in Asia Minor, vols. I-II. Oxford 1993. S. Mitchell, "The Administration of Roman Asia from 133 BC to AD 250", Ed. W. Eck, Lokale Autonomie und römische Ordnungsmacht in den kaiserzeitlichen Provinzen vom 1. bis 3. Jahrhundert. Münih (1999) 17-46.

H. Mouritsen, The Freedman in the Roman World. Cambridge 2011.

H. Müller, "Claudia Basilo und ihre Verwandtschaft". Chiron X (1980) 457-484.

W. Dittenberger, Orientis Graecae Inscriptiones Selectae I-II. Leipzig 1903-1905.

P. Pensabene, "Il marmo lunense nei programmi architettonici e statuari dell'occident eromano". Ed. V. Garcia-Entero, El marmor en Hispania: explotacion, uso y difusion en epoca romana. Madrid (2014) 17-48.

H. Pelham, The Imperial Domains and the Colonate. Londra 1890.

H.-G. Pflaum, Les carrières procuratoriennes équestres sous le Haut-Empire romain I-II. Paris 1960.

Eds. E. Groag, A. Stein - L. Petersen, Prosopographia Imperii Romani saec. I-III. Berlin 1933-.

D. Potter, "Procurators in Asia and Dacia under Marcus Aurelius: A Case Study of Imperial Initiative in Government". ZPE CXXIII (1998) 270-274.

W. M. Ramsay, The Social Basis of Roman Power in Asia Minor. Aberdeen 1941. Revue des études anciennes. Bordo 1899-

L. Robert, "Nonnos et les monnaies d'Akmonia de Phrygie".Journal des Savants III-IV (1975) 153-192.

M. Rostovtzeff, The Social and Economic History of the Roman Empire. Oxford ${ }^{2}$ 1957.

J. Röder, "Marmor phrygium. Die antiken Marmorrüche von Iscehisar in Westanatolien". JDAI LXXXVI (1971) 253-312.

A. Schulten, Die römischen Grundherrschaften. Eine agrarhistorische Untersuchung. Weimar 1896.

Supplementum Epigraphicum Graecum. Leiden - Amsterdam 1923-.

J. Strubbe, "A Group of Imperial Estates in Central Phrygia". Ancient Society VI (1975) 229-250.

W. Tabbernee - P. Lampe, Pepouza and Tymion: The Discovery and Archeological Exploration of a Lost Ancient City and an Imperial Estate. Berlin New York 2008.

B. Takmer, "Kotiaion ve Synaos'tan Üç Yeni Yazıt". Ed. S. Ünan, Kütahya Müzesi 2017 Yıllığı. Ankara (baskıda).

Transactions and Proceedings of the American Philological Association, NS Atlanta 1974-.

P. Thonemann, "The Women of Akmoneia" JRS C (2010) 163-178.

P. Thonemann, The Maeander Valley: A Historical Geography from Antiquity to Byzantium. Cambridge 2011.

P. Thonemann, "Phrygia: An Anarchist History, 950 BC-AD 100". Ed. P. Thonemann, Roman Phrygia. Culture and Society. Cambridge (2013) 1-40. 
Türktüzün - Ünan 2017

Waelkens 1985

Waelkens 1986

Weaver, Repertorium

Weaver 1972

Verboven 2011

Vitale 2012

Vitale 2015

Zgusta 1984

ZPE

Zuiderhoek 2009
M. Türktüzün - S. Ünan, "Servi Mahallesi Kurtarma Kazısı". Ed. S. Ünan, Kütahya Müzesi 2016 Yıllığı. Ankara (2017) 33-64.

M. Waelkens, "From a Phrygian Quarry. The Provenance of the Statues of the Dacian Prisoners in Trajan's Forum at Rome". AJA LXXXIX (1985) 641-653.

M. Waelkens, Die kleinasiatischen Türsteine. Typologische und epigraphische Untersuchungen der kleinasiatischen Grabreliefs mit Scheintür. Mainz 1986.

P. Weaver, Repertorium Familiae Caesarum - http://www.uni-koeln.de/ philfak/ifa/altg/eck/weaver.htm

P. R. C. Weaver, Familia Caesaris. A Social Study of the Emperor's Freedmen and Slaves. Cambridge 1972.

K. Verboven, "The Freedman Economy of Roman Italy". Eds. S. Bell - T. R. Ramsby, Free at Last! The Impact of Freed Slaves on the Roman Empire. Londra 2011.

M. Vitale, Eparchie und Koinon in Kleinasien von der ausgehenden Republik bis ins 3. Jh. n. Chr. (AMS 67), Bonn 2012.

M. Vitale, "Imperial Phrygia: A "Procuratorial Province" Governed by liberti Augusti?", Philia I (2015) 33-45.

L. Zgusta, Kleinasiatische Ortsnamen. Heidelberg 1984. Zeitschrift für Papyrologie und Epigraphik. Bonn 1967-.

A. Zuiderhoek, The Politics of Munificence in the Roman Empire: Citizens, Elites and Benefactors in Asia Minor. Cambridge 2009. 